\title{
EVALUATION OF OUTDOOR SPACES WITHIN THE CAMPUS "AL-AZHAR UNIVERSITY IN NASR CITY AS A CASE STUDY"
}

\author{
Samah Mohamed Fahim*1, Haytham Sadiq Salim ${ }^{2}$ and Ahmed Saad Dabour ${ }^{2}$ \\ ${ }^{1}$ Department of Architecture, Faculty of of Engineering for Girls, Al-Azhar University, \\ Cairo, Egypt \\ ${ }^{2}$ Department of Architecture, Faculty of Engineering, Al-Azhar University, Cairo, Egypt \\ *Corresponding Author E-mail:samahfahim@azhar.edu.eg
}

\begin{abstract}
Campus open spaces play an important role in meeting socialization and personal development needs of youth. Various studies have shown that space use of youth is different from that of general society: particularly their psychosocial nature and the activities they carry out toward this nature differ from those of the children and adults. However, only a limited number of studies have produced findings on the needs of youth toward obtaining gains related to development of psychosocial nature required to carry out the activities aimed at meeting such needs. This study analyzed the use of campus open spaces by youth .

The most preferred 3 places in study area have been chosen and with behavioral observation, the activity types occurred in these places were identified. Which of these activities are for personal development and which of them are for social development were determined.
\end{abstract}

\section{KEYWORDS: Youth, Personal and social needs, Campus open spaces, Activity types, Haman Behavior}

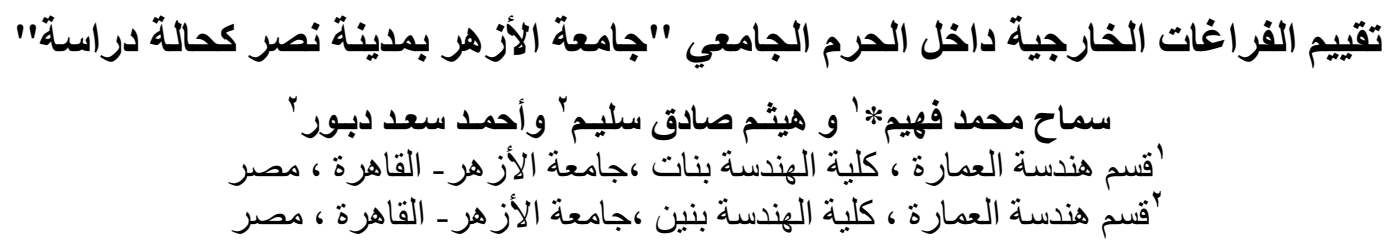

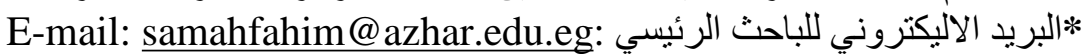

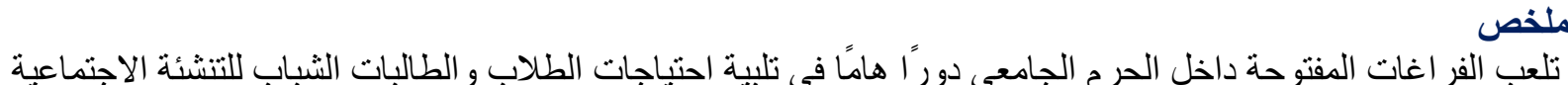

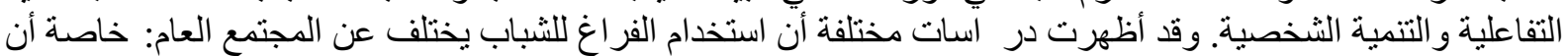

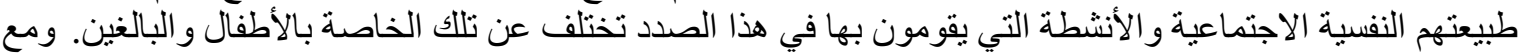

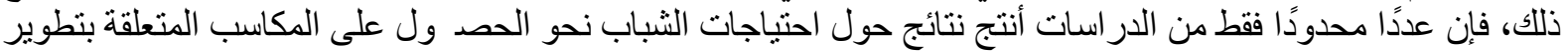

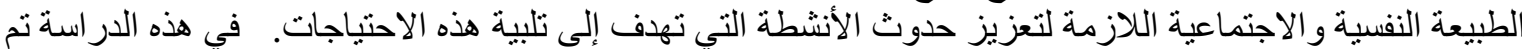

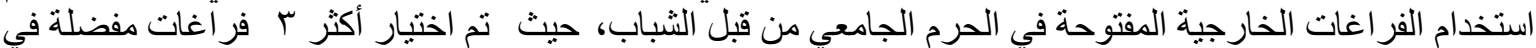

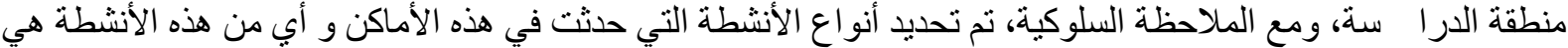
للتطوير الثخصي و للتنمبة الاجتماعية.

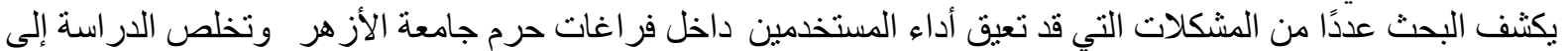

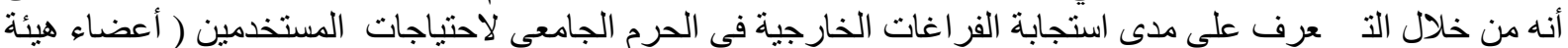

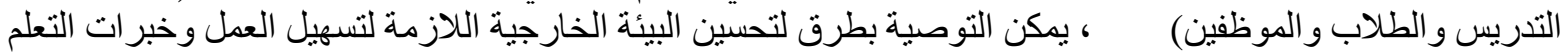

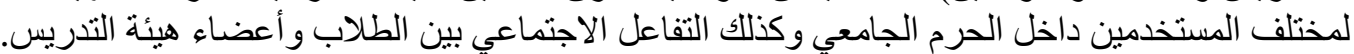

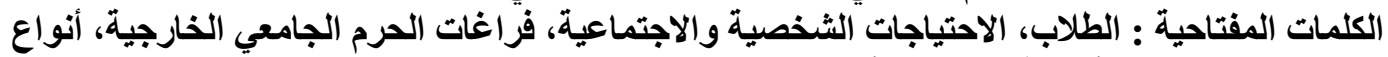
الأنشطة، السلوك الأنسانى الأن 


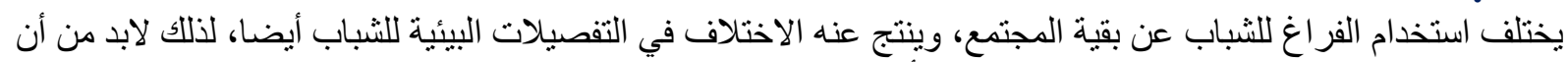

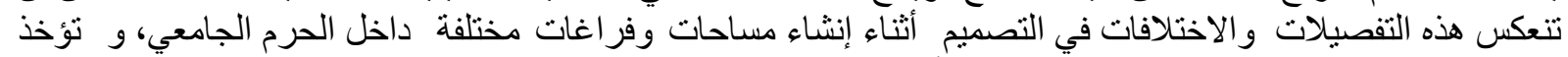

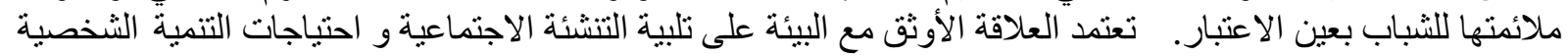

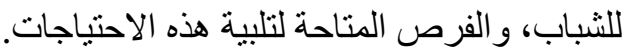

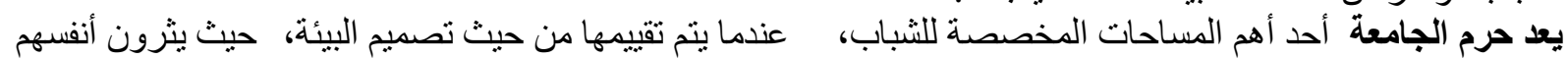

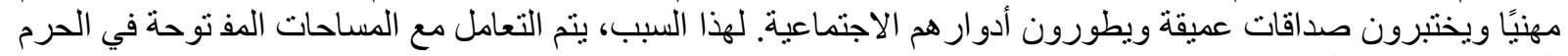
الجامعي في هذه الدر اسة.

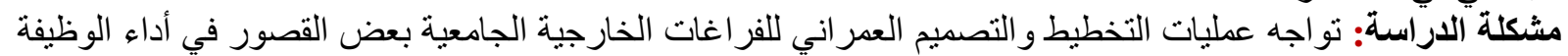

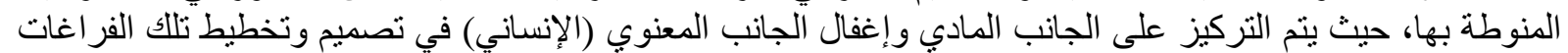

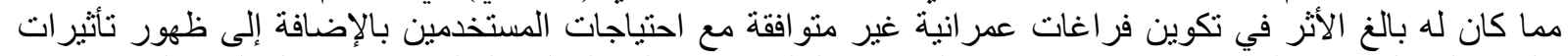

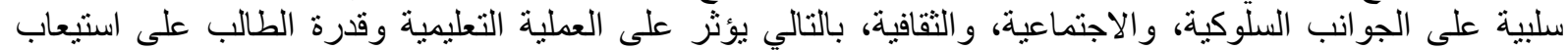

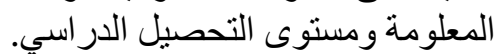

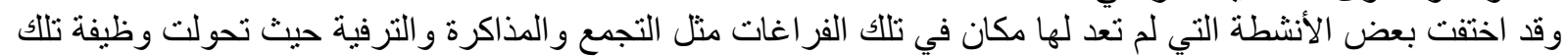

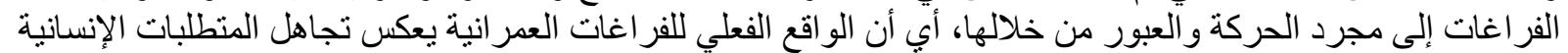

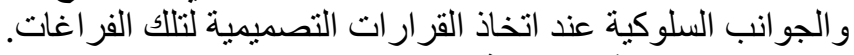

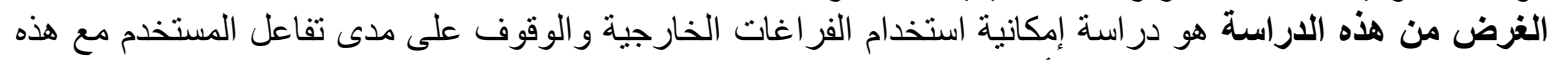

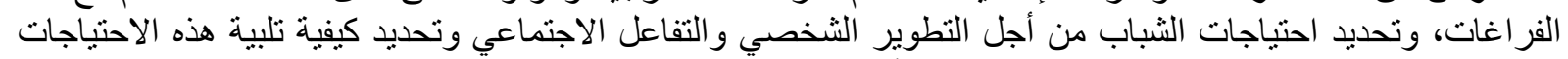

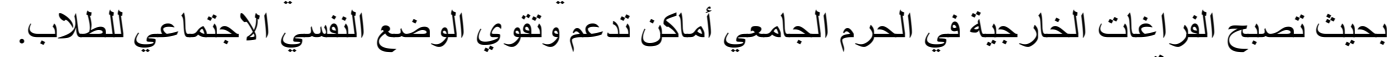

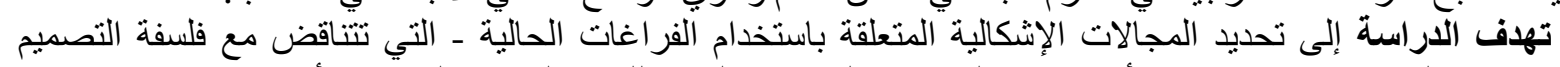

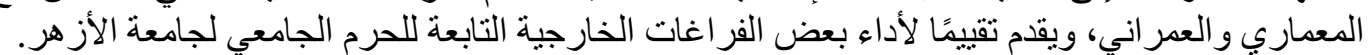

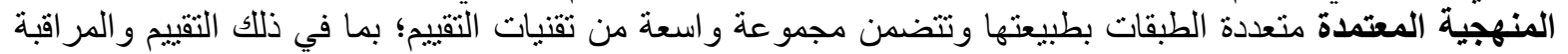
المباشرة والتصوير الفوتو غر افي، ورسم الخُونة الخرائط السلوكية، واستبيانات المسح.

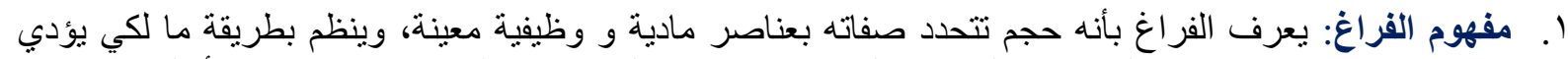

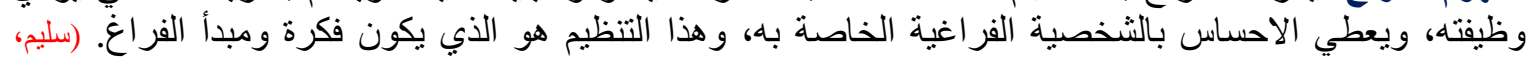

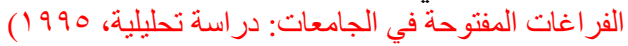

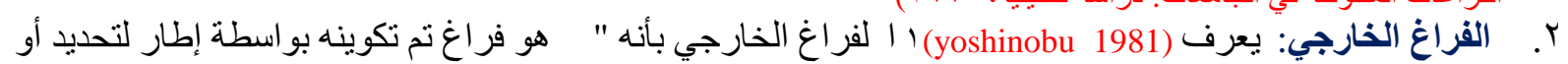

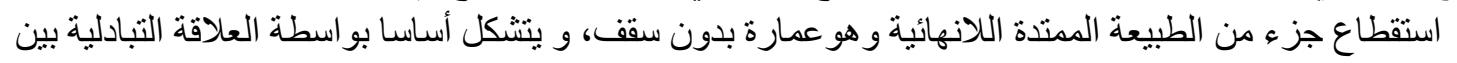

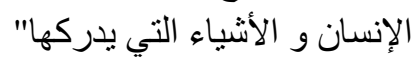

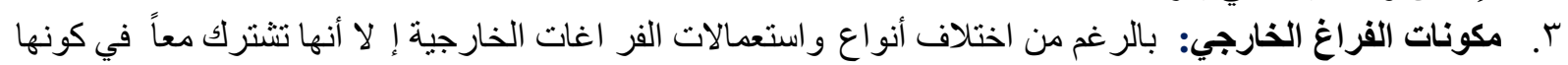

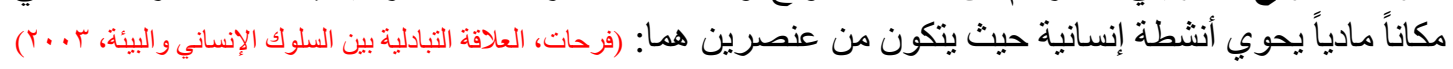

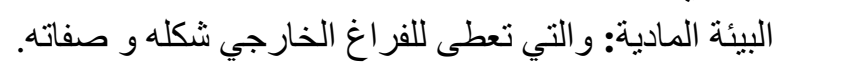

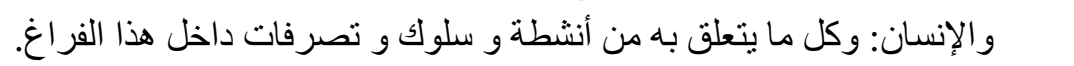

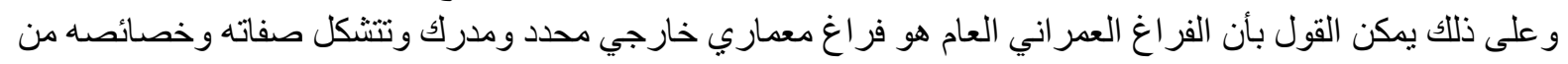

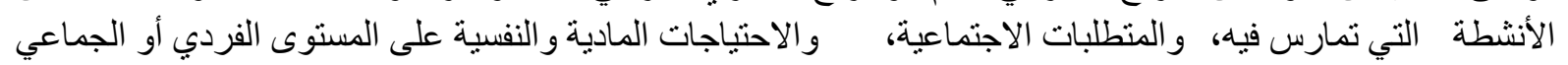

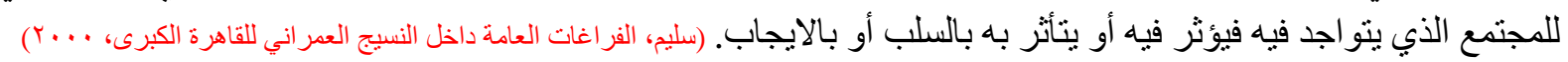

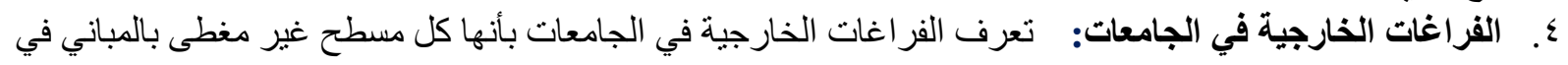

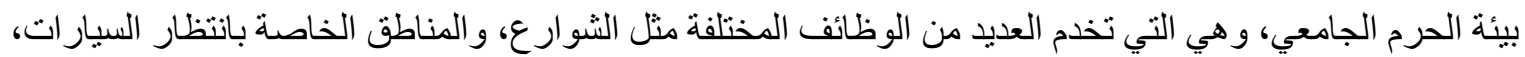

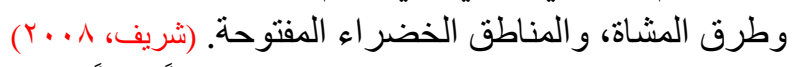

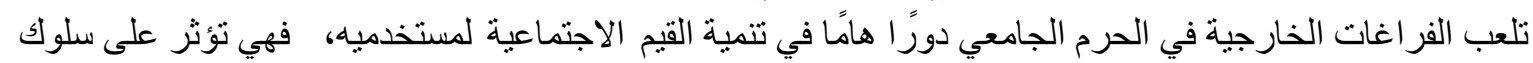

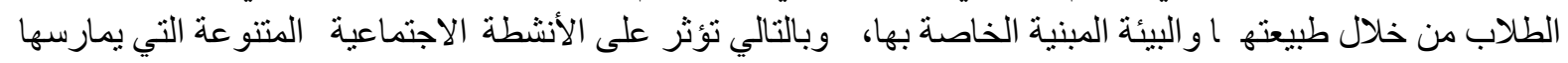

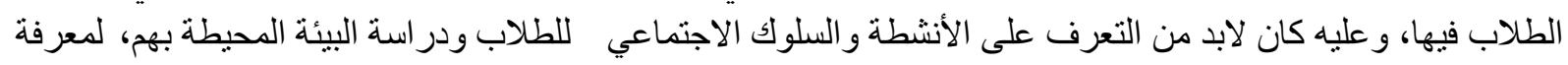
احتياجاتهم الاجتماعية وكذلك منطلباتهم الشخصية، و التي تساعدهم على ممارسة الأنشطة الخاصة بهل بهم بشكل لائق.

\footnotetext{
${ }^{1}$ Ashihara, Yoshinobu. Exterior design in architecture. Van Nostrand Reinhold Company, 1981.
} 


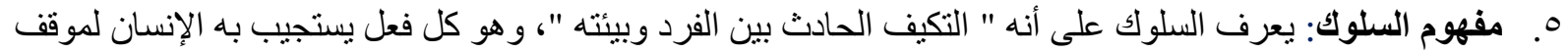

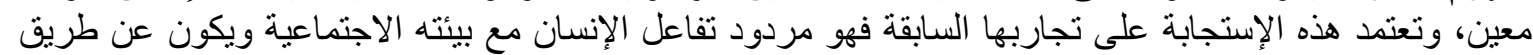

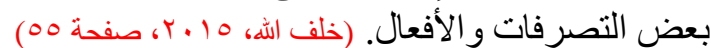
إذن فالسلوك هو النتاج الطبيعي للتأثير المتبادل بين الإنسان بقدر اتها و إمكاناته العضوية و النفسية و العقلية و الثقافية وتجاربه النيه

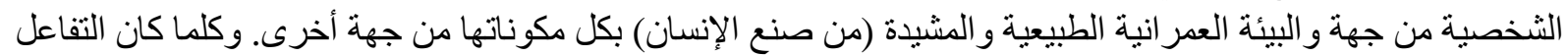

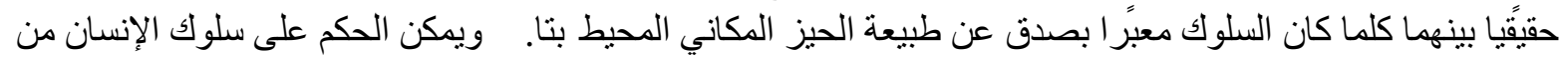

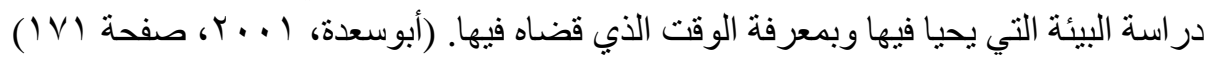

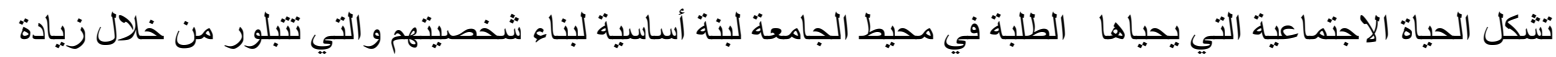

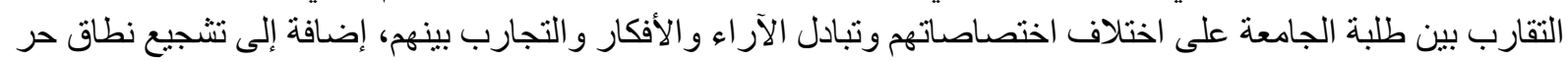

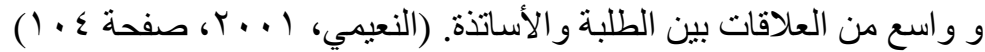

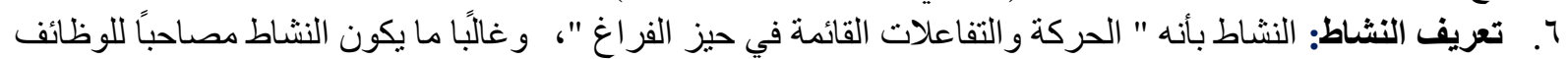

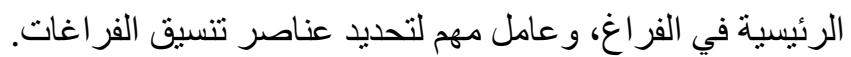

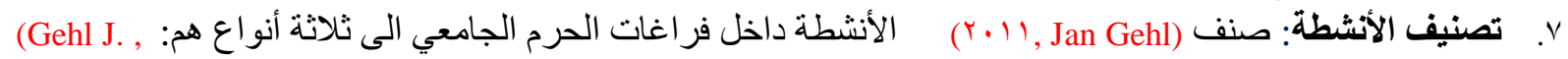
.Life between buildings, 2011, p. 9)

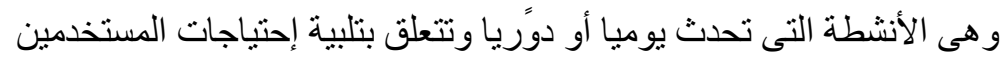
†

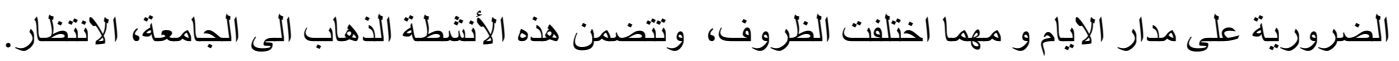

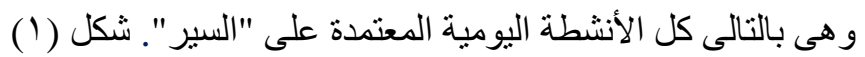

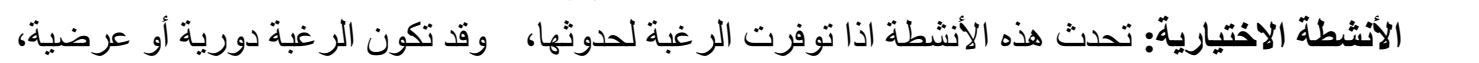

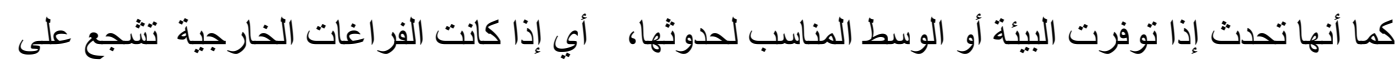

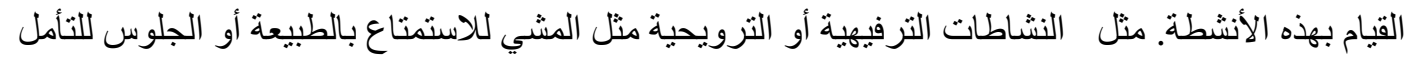

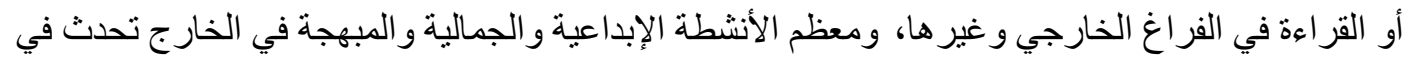

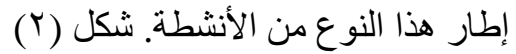

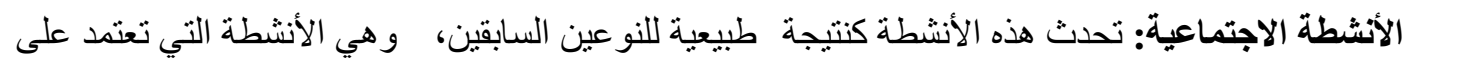

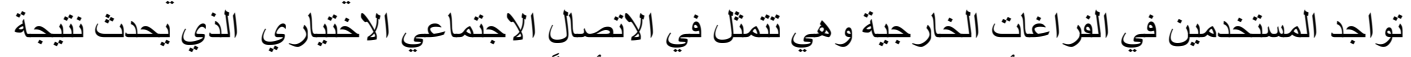

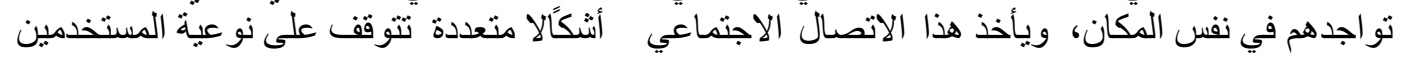

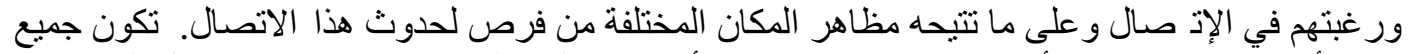

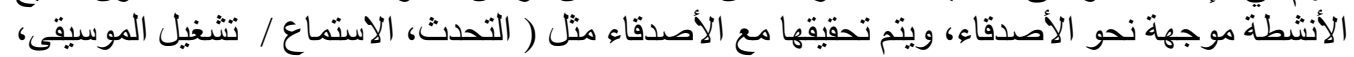

قضاء الوقت مع الأصدقاء، الدراسة، الاجتماع، الحفلات، الأ... إلخ).

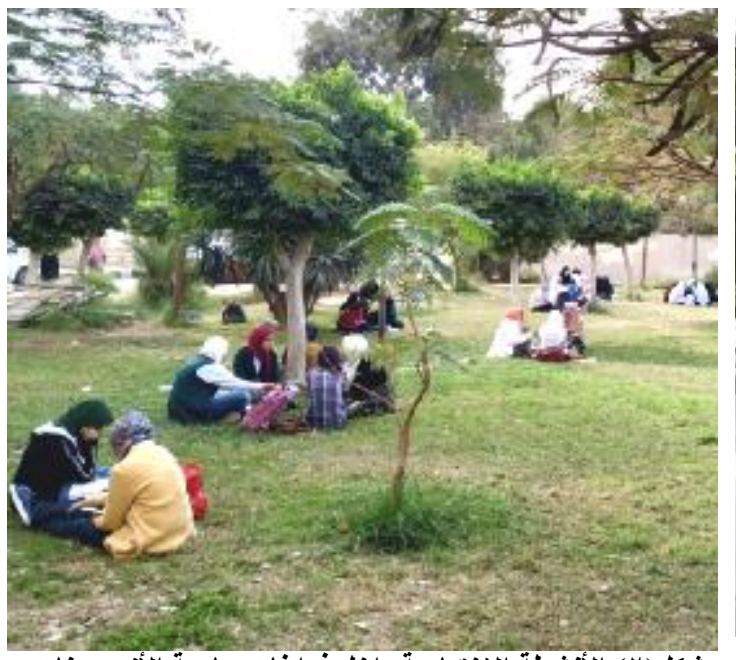

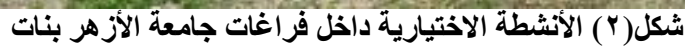

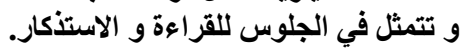

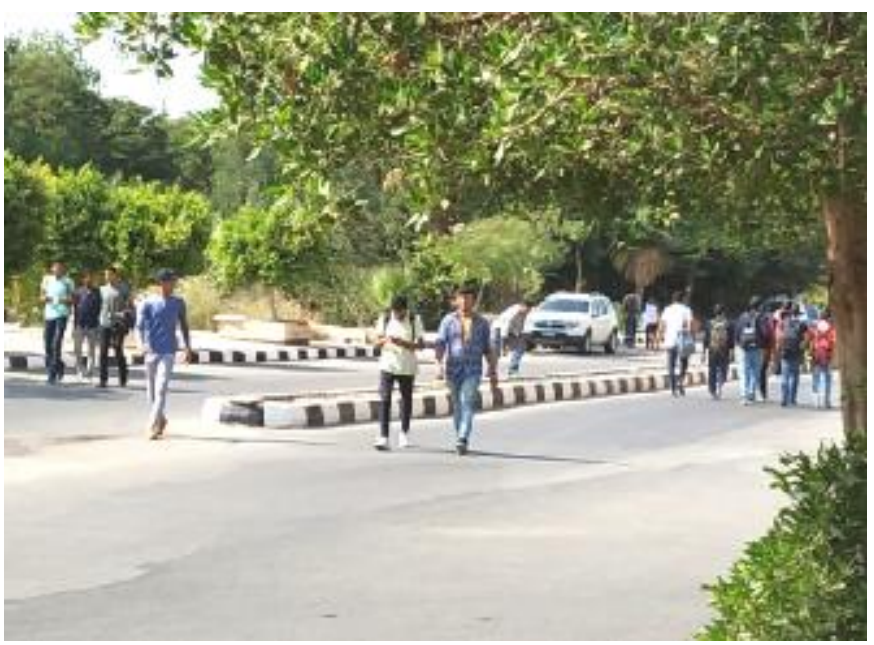

شكل ( 1 ) الأنشطة الضرورية داخل فراغات جامعة الأزهر بنين و تتمثل في السير والتنقل من فراغ فات جأخعة. 


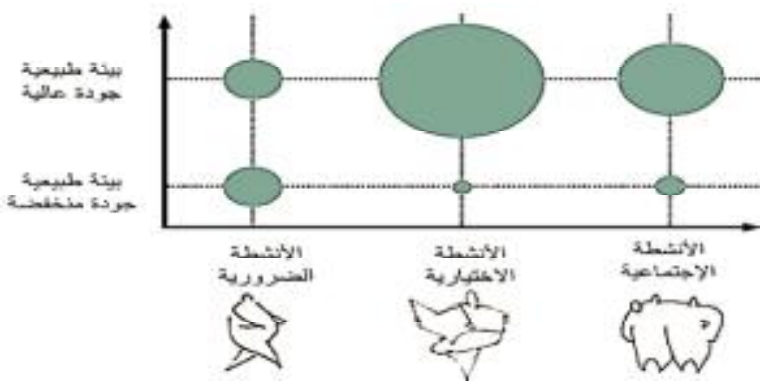

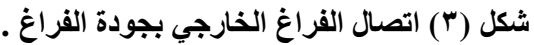

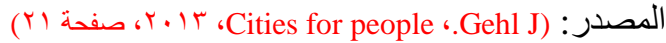

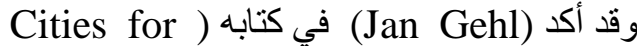
(people, 2010

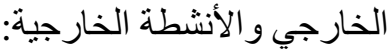

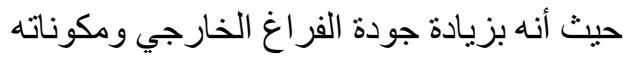

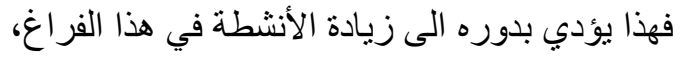

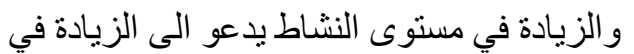

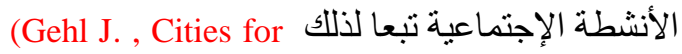

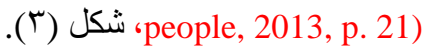

^. الاحتياجات المتعلقة بطلاب الجامعة: (التتمية الثخصية ـ التنشئة الاجتماعية)

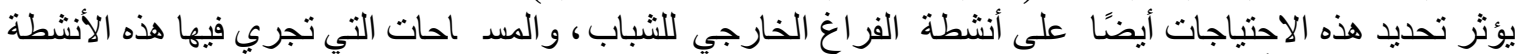

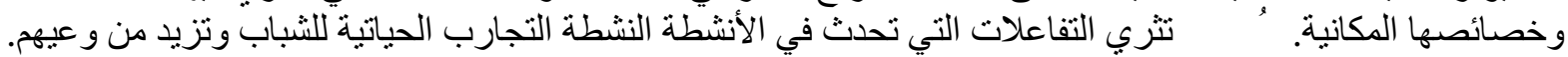

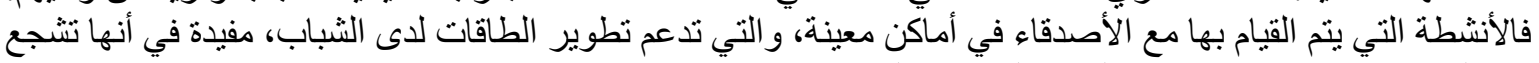

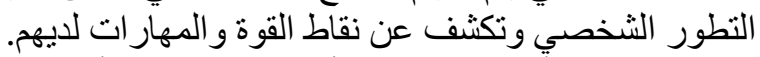

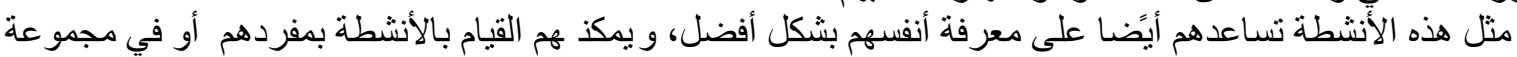

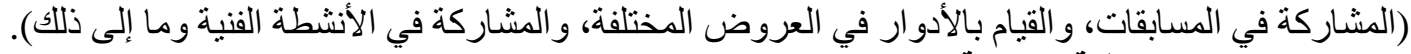
9. اختيار وتحديد منطقة الدراسة:

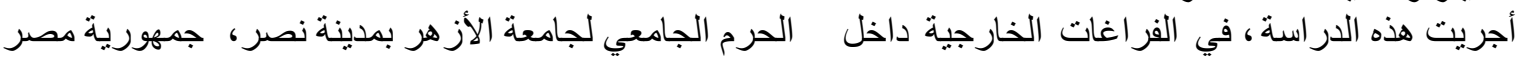
العربية.

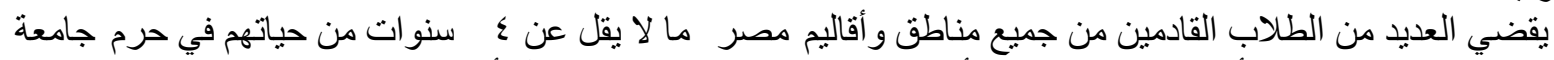

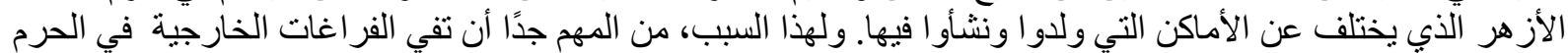

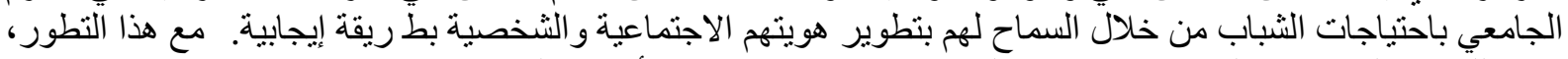

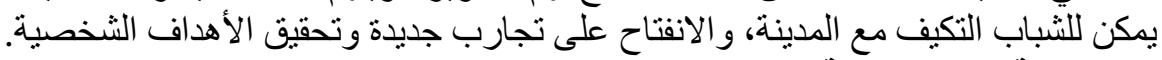

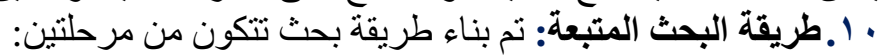

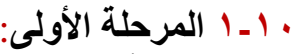

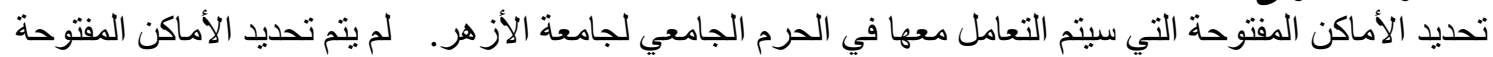

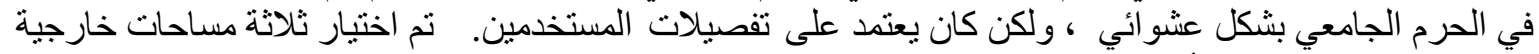

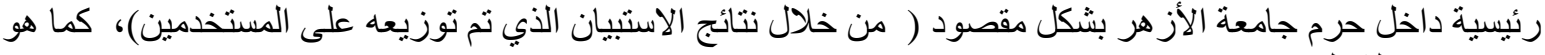

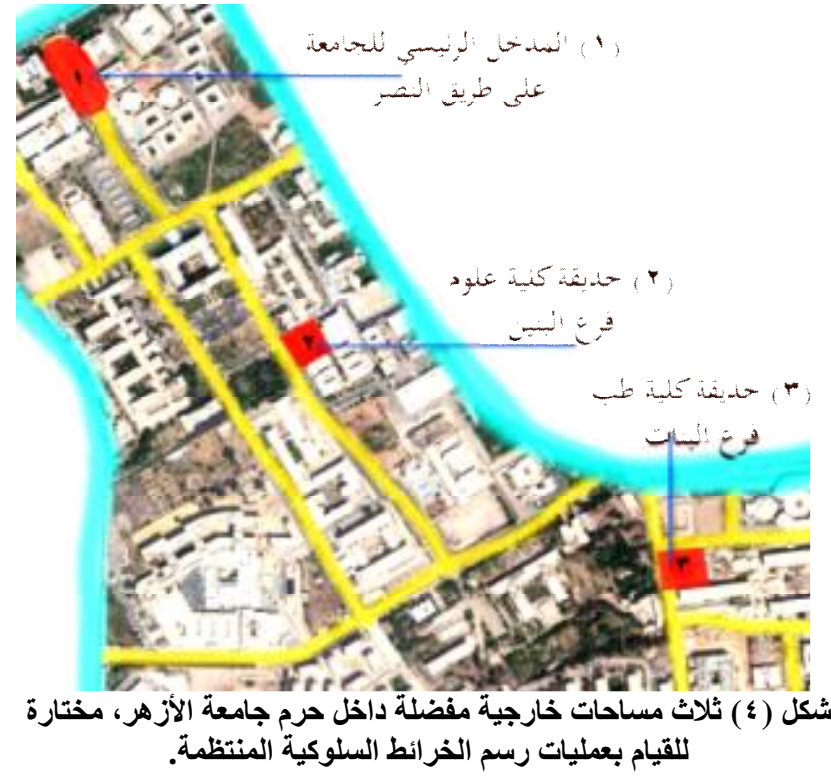

بالمدخل الرئيسي للجامعة أغئر

موضح في الثكل (ع) (1).

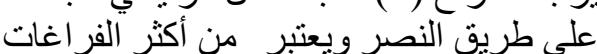

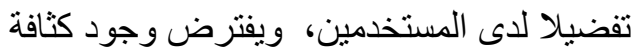

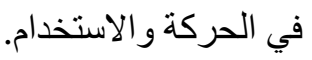

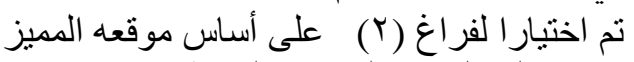

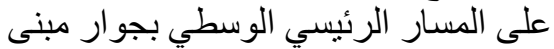
الإدارة وارتباطه بكلية العلوم للبنين.

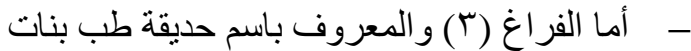

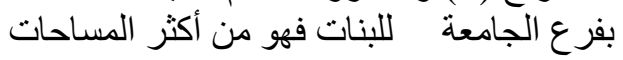

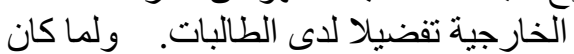
الغرض من ذلارك هو دراسة إمكانية استخدام المساحات الخارجية و الوقوف على دلى مدى تفاعل

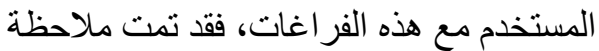
كل من المساحات الثنلاث عدة مر ات مع فترة فئرة متداخلة بما في ذلك بداية ونهاي ة الفصول و المحاضر ات ووقت الفاصل بينهما. 


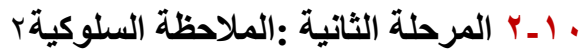

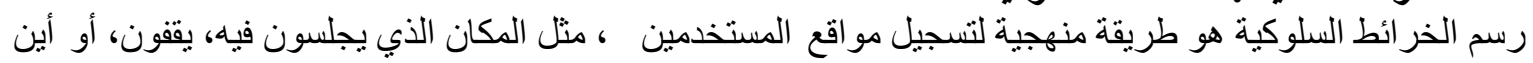

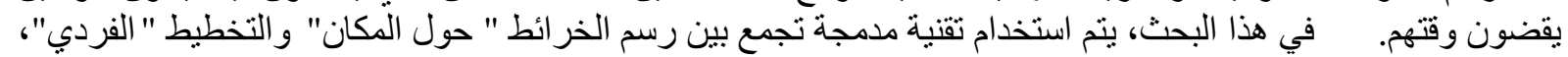

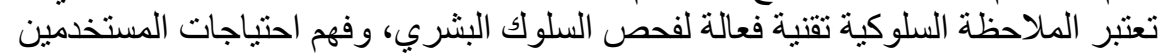
(salama, 2012, 2009)

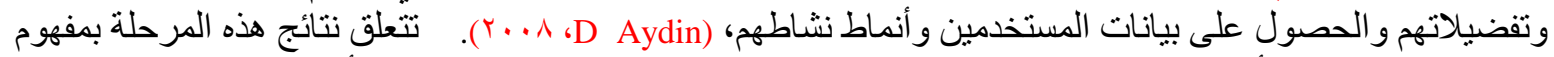
النشاط، حيث تم تحديد الأنشطة التي يقوم بها المستخدمون في المساحات الخارجية المختارة ( و وأي منها للتطوير الثخصي

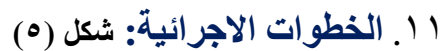

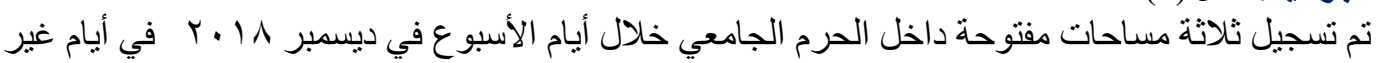

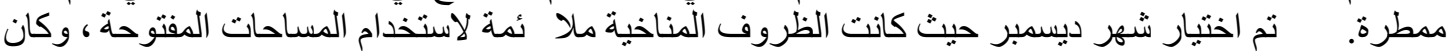

الطلاب لا يز الون في الحرم الجامعي.

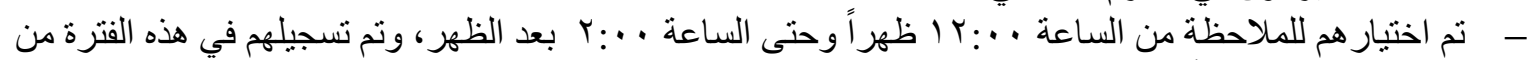

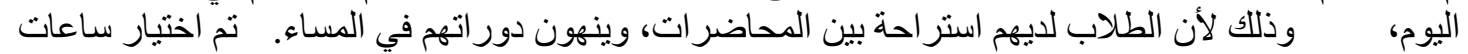

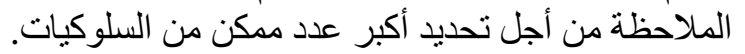

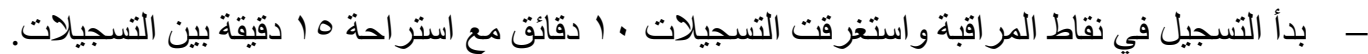

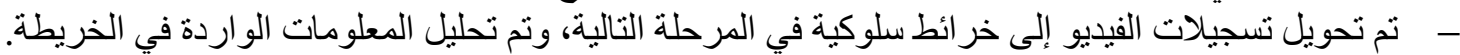

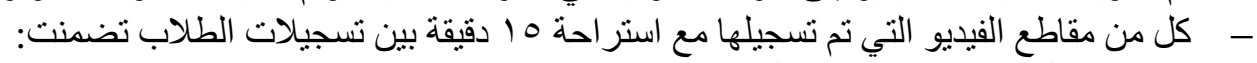

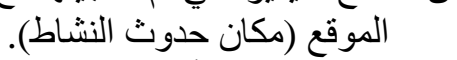
† †وع وطبيعة الأنشطة التي تم القيام بها (الحديث، المذاكرة، وتناول الطعام / الثرب، وما إلى ذلك).

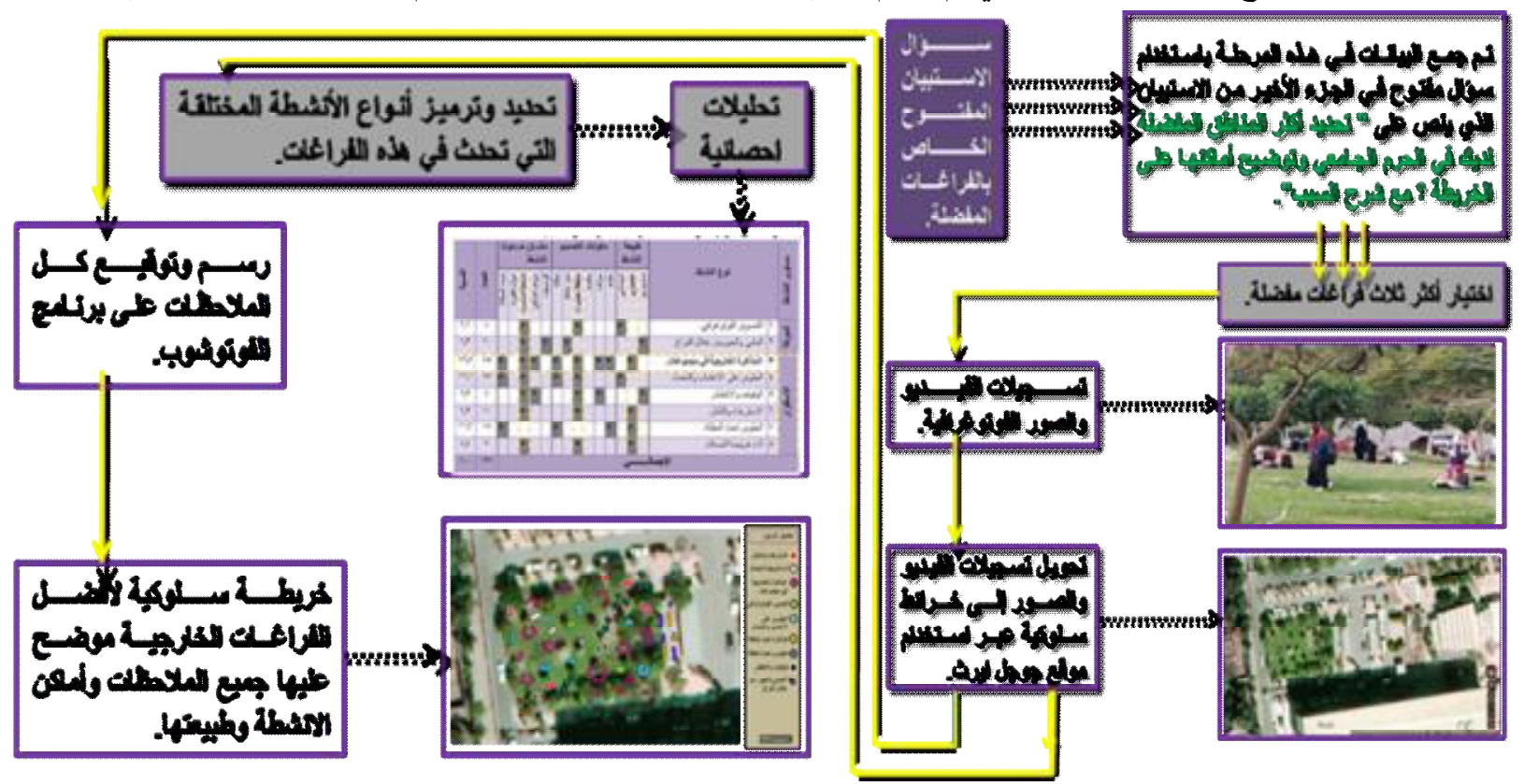

شكل (0) رسم تخطيطي للخطوات الإجرائية المتبعة لرسم الخرائط السلوكية.

2 رسم الخرائط السلوكية (Gehl S. B., 2013, p. 26) عملية رسم الخر ائط هي ببساطة رئ رسم خريطة لما يحدث في مخطط الفضاء أو المنطقة محل التحقيق. ثُستخدم هذه التقنية عادة للإشارة

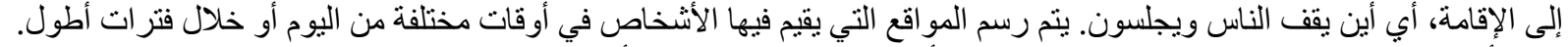

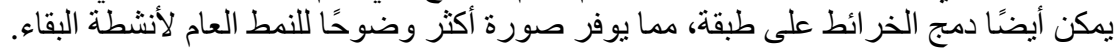

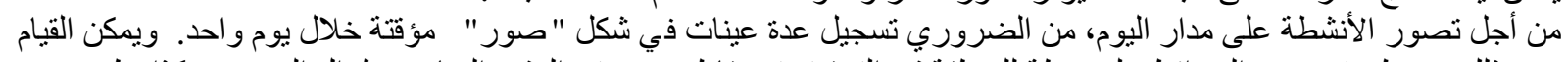

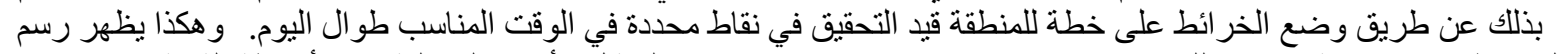

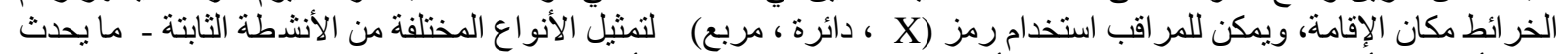

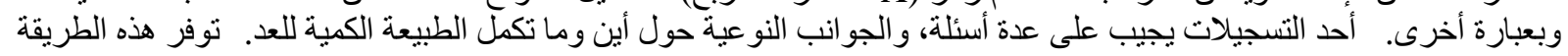

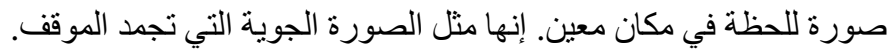


r ا ـ الفراغات المختارة للار اسة:

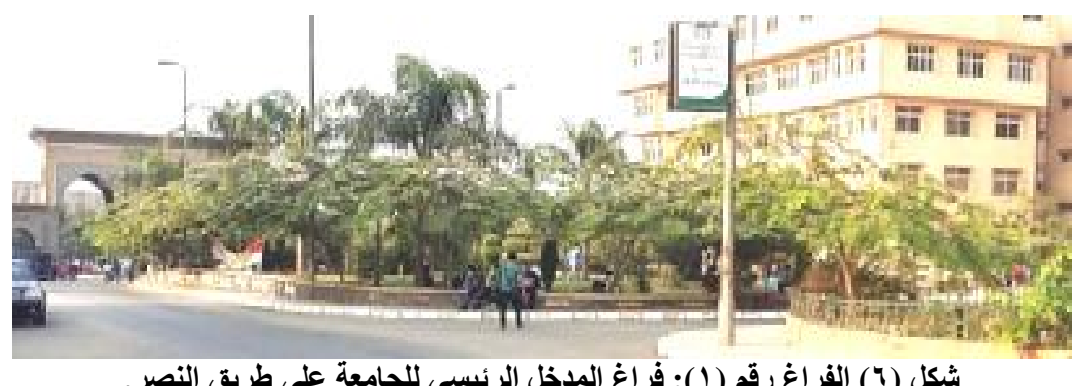

شكل (؟) الفراغ رقم (1) فراغ المدخل الرئيسي للجامعة على طريق النصر.

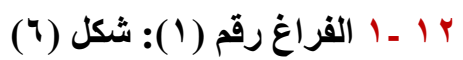

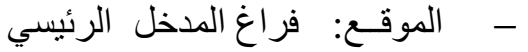

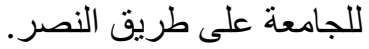

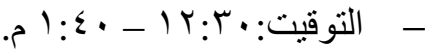

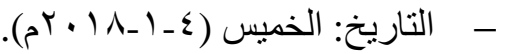

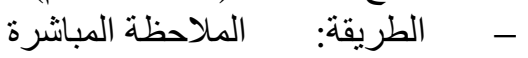

و الخريطة السلوكية.

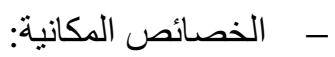

† قريب من الطريق الرئيسي والبو ابة الرئيسية (مكان مناسب لانتظار الأصدقاء بعد انتهاء اليوم الدراسي).

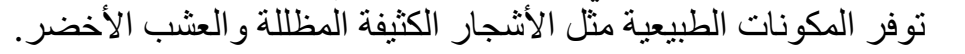

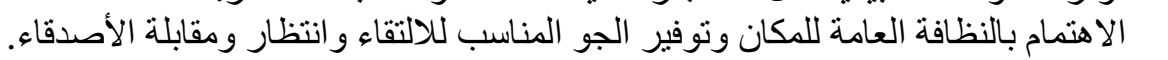

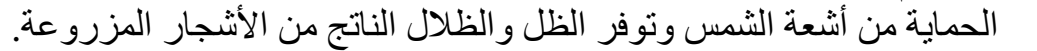

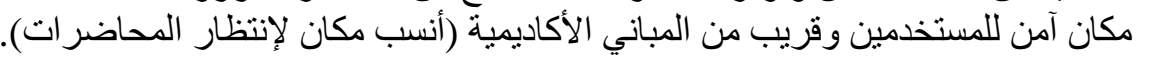
† رؤية بانور امية دون عو ائق للمنطقة المحيطة تسمح بمشاهدة الأشخاص المارين.

جدول (1) الأنشطة وتردداتها للفراغ رقم (1).

\begin{tabular}{|c|c|c|c|}
\hline النسبة & العدد & الانشطة & \\
\hline$r v, r$ & $\wedge$. & الجلوس على حواف ورصيف الفراغ. & 1 \\
\hline 9,9 & rq & الجلوس على الأعشاب الخضراء. & r \\
\hline 10,8 & $\leqslant 0$ & الوقوف والإنتظار. & $r$ \\
\hline$V, r$ & Y & المذاكرة الخارجية فردى ومجموعات. & $\varepsilon$ \\
\hline $1 r, 9$ & \& & التحدث مع الأصدقاء. & $\bullet$ \\
\hline r, & 9 & الإسترخاء والنوم على العثب الأخضر. & 7 \\
\hline $1, \mathrm{~V}$ & $\bullet$ & التصوير الفوتوغرافي. & v \\
\hline$\wedge, 9$ & rq & المشي والعبور بجوار الفراغ. & $\Lambda$ \\
\hline $1, \mathrm{~V}$ & 0 & أداء فريضة الصلاة. & 9 \\
\hline $1 \cdot, 9$ & rr & المشاهدة والمر اقبة. & 1. \\
\hline $1 \cdots$ & rqr & الاجمالي & \\
\hline
\end{tabular}

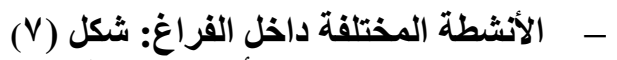

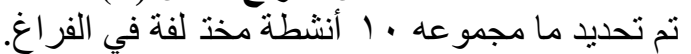

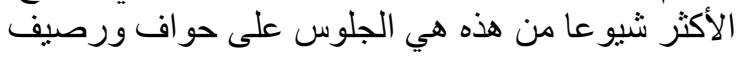

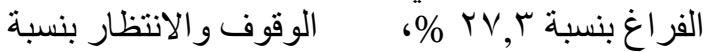

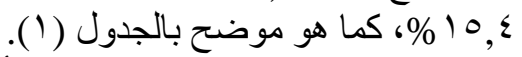

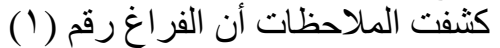

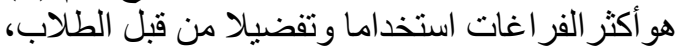

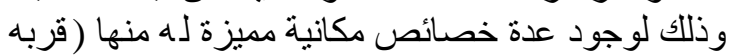

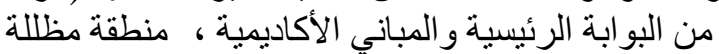

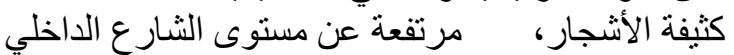

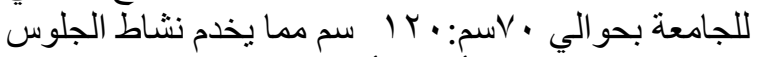

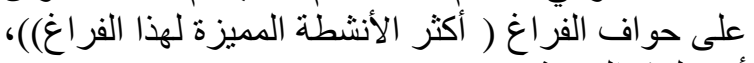
أدت لـذه النتيجة.

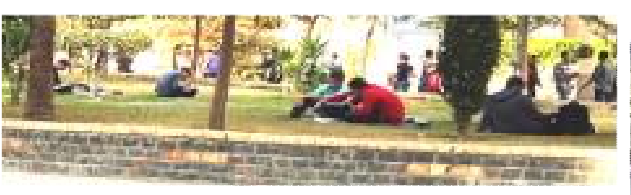

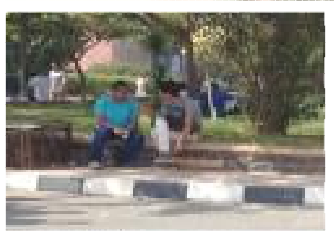
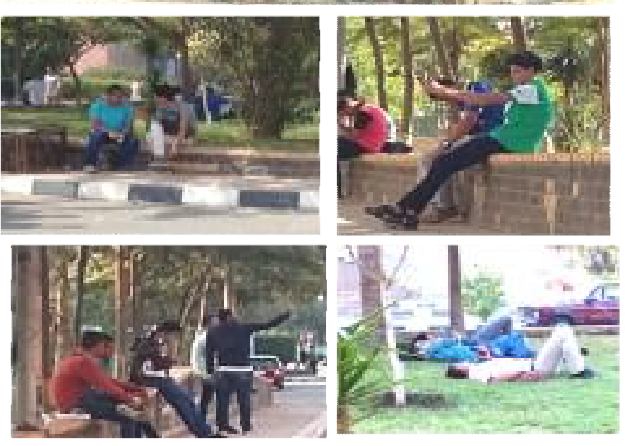

شكل (V) الأنشطة المختلفة داخل الفراغ رقم (1) (1).

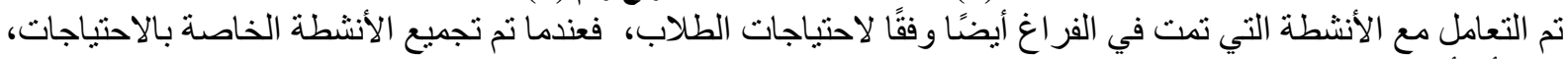

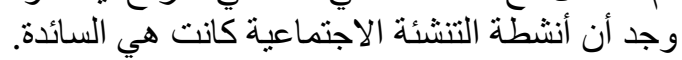




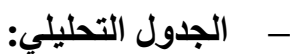

يحتوي على خمسة عناصر أساسية لفحص العلاقة بين مستوى وطبيعة الأنشطة، استخدام مكونات التصميج ومكان

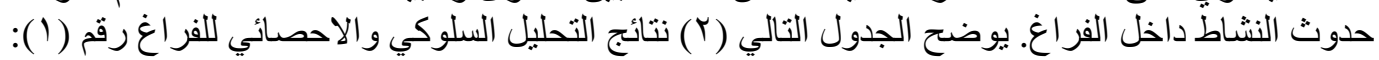
جدول (Y) نتائج التحليل السلوكي والإحصائي للفراغ رقاغ رقم (1).

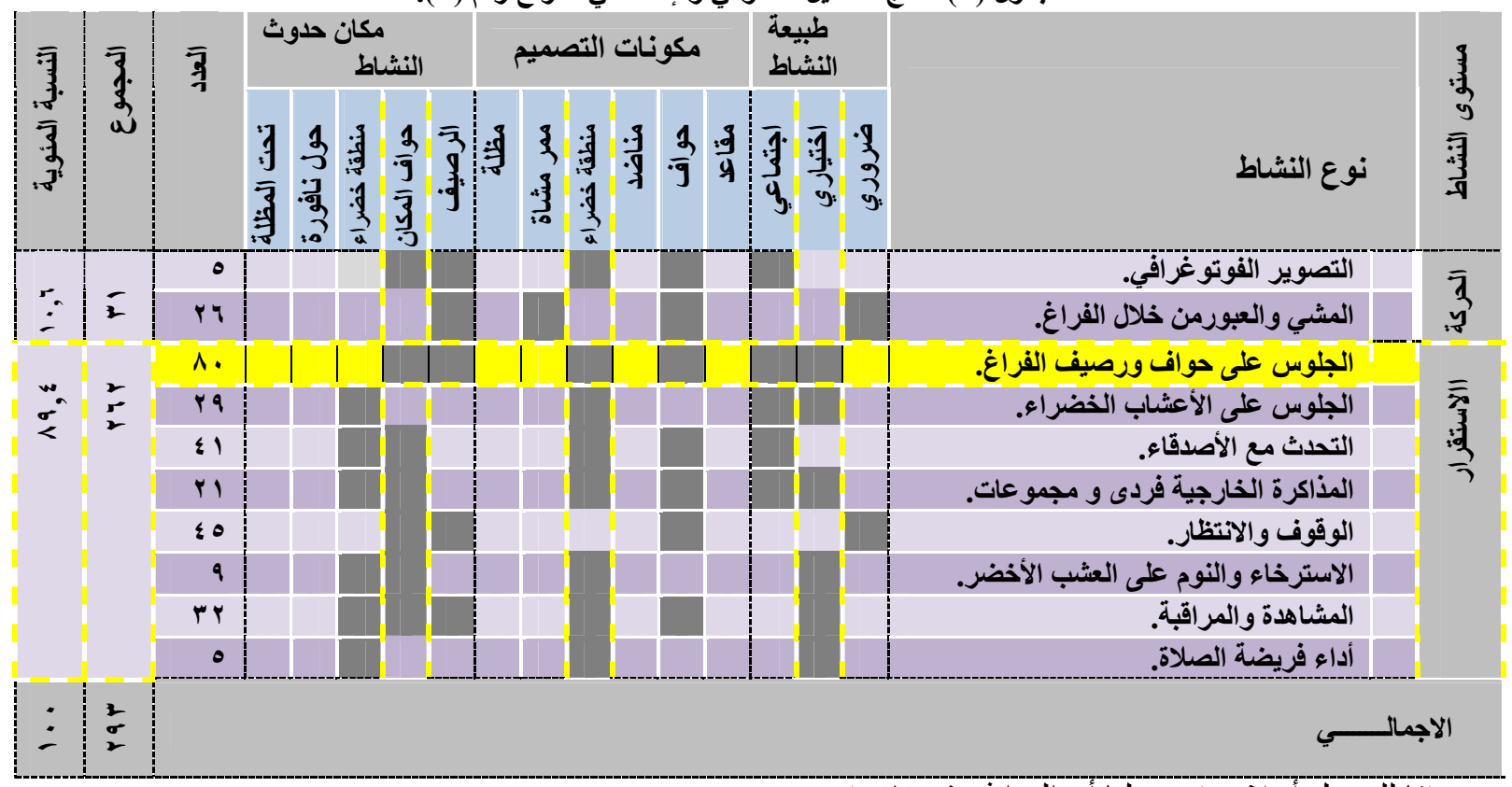

وفقا للجدول أعلاه، يتضح لنا أن الفر اغ رقم ( () يتميز ب:

\begin{tabular}{|c|c|c|}
\hline نقاط الضعف: & نقاط القوة: & \\
\hline 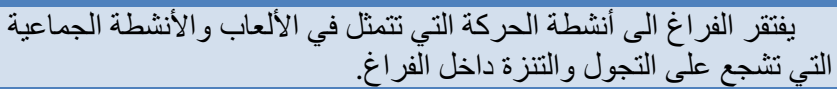 & 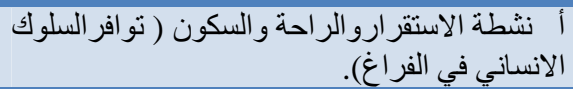 & 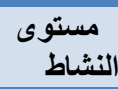 \\
\hline 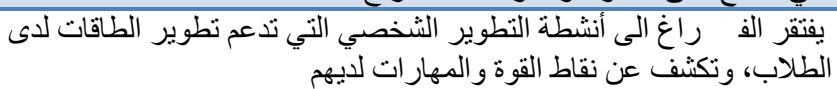 & التتشئة الاجتماعبة). حواف ورصيف الفراغِ (أنثطة & الميز النشاط \\
\hline 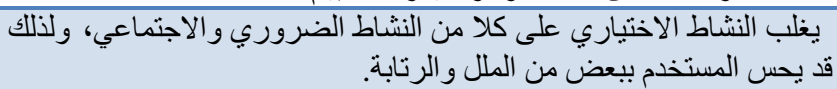 & الجيدة لمكونات الفراغ). مما يدل على الجودة الاجمالية & النشاط \\
\hline 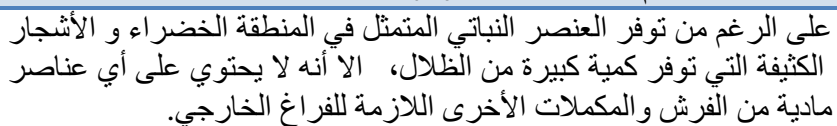 & 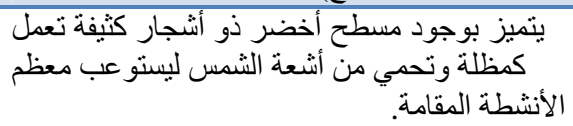 & التصميز \\
\hline 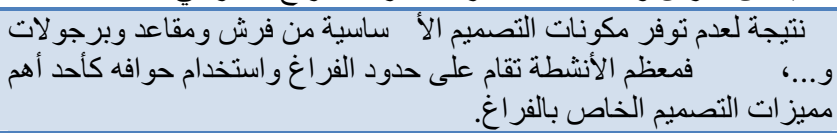 & 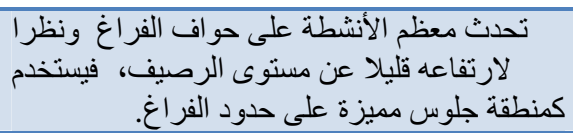 & النشاط حكان \\
\hline
\end{tabular}




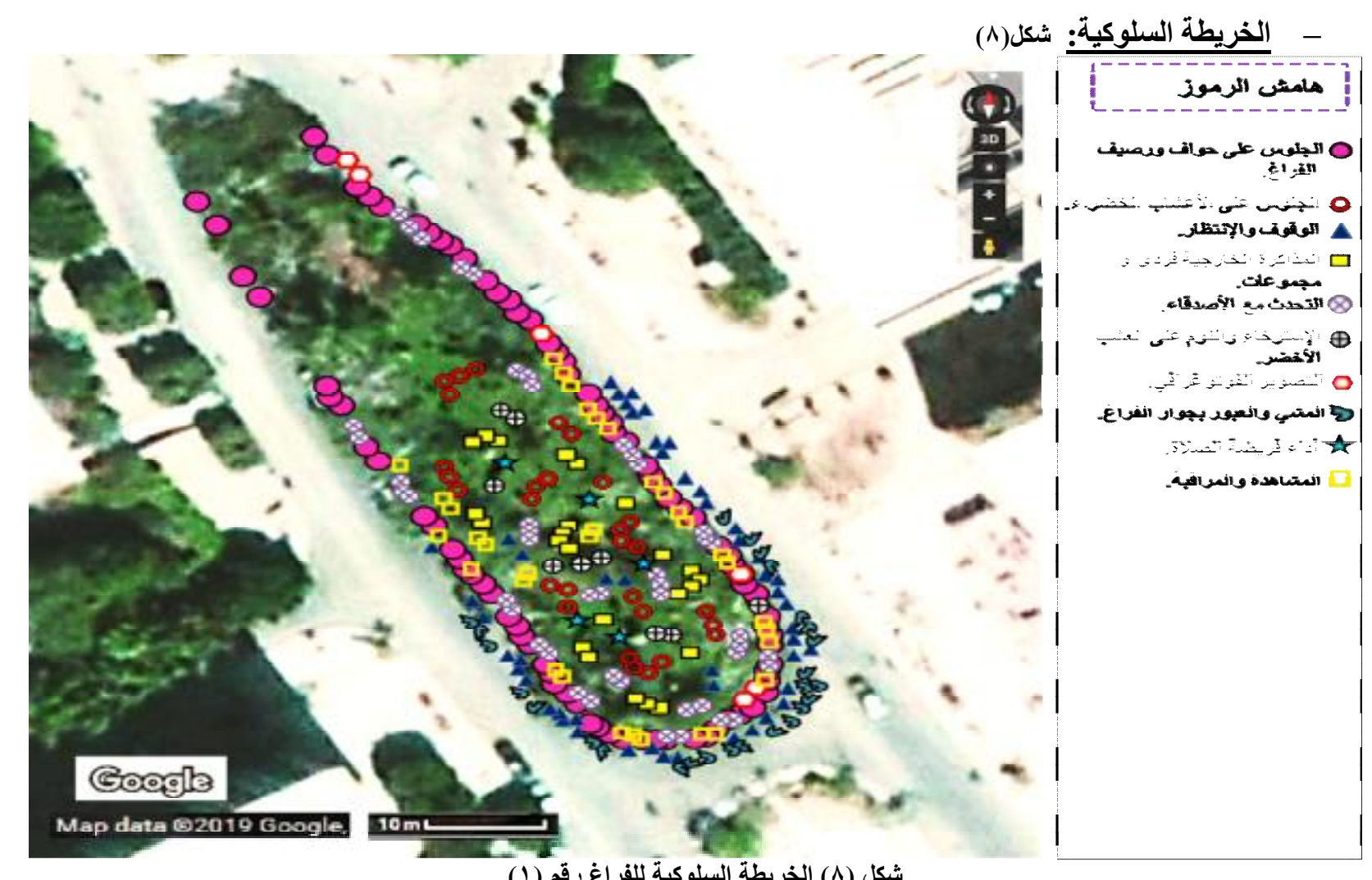

شكل (^) الخريطة السلوكية للفراغ رقم (1).

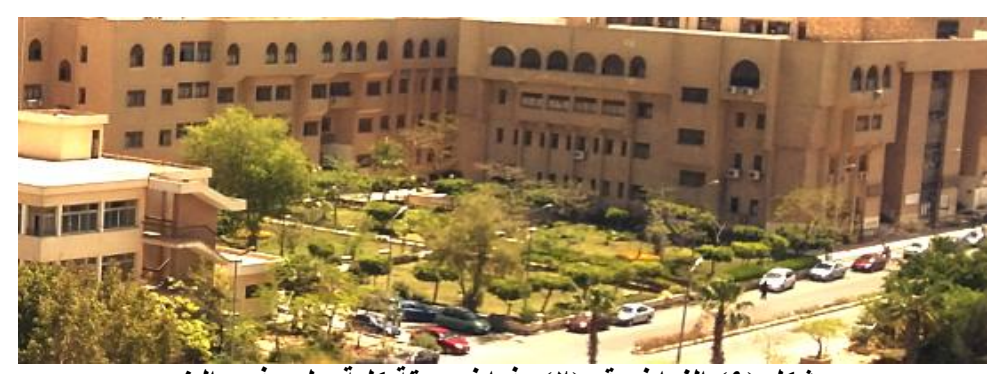

شكل (q) الفراغ رقم (ץ): فراغ حديقة كلية علوم فرع البنين.

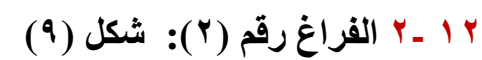

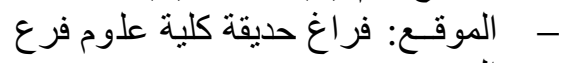
البنين. -

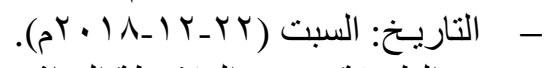

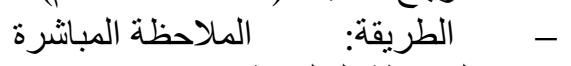
و الخريطة السلوكية.

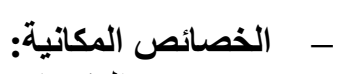

† ت فوفر المكونات الطبيعية مثل الأشجار الكثيفة المظللة والعشب الأ خضر وبعض المكملات المادية التي تتمثل في المقاعد و المظلات الخفات الخفيفة.

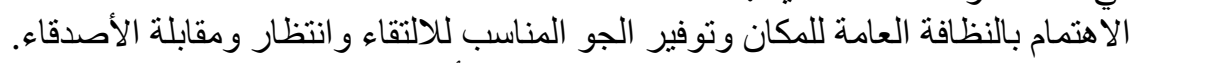

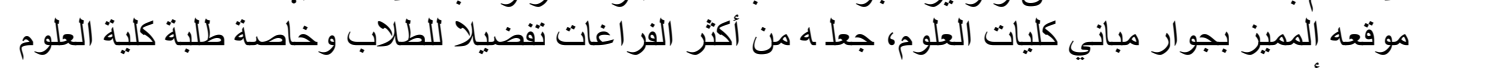
بجميع أقسامها.

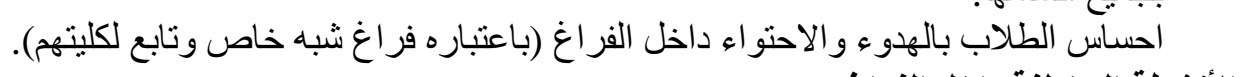

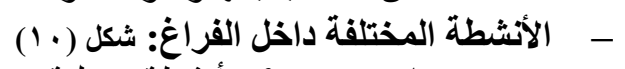

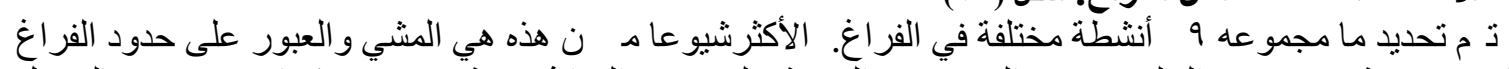

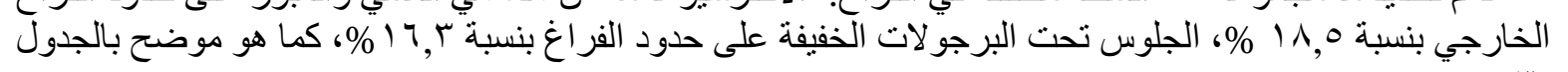


جدول (r) الأنشطة وتردداتها للفراغ رقم (r).

\begin{tabular}{|c|c|c|c|}
\hline النسبة & العدد & الانشطة & \\
\hline$\wedge, r$ & 10 & الجلوس على حواف ورصبف الفراغ. & 1 \\
\hline $1 \leq, 1$ & r4 & الجلوس على الأعشاب الخضر اء. & r \\
\hline $1 \cdot, 9$ & $r \cdot$ & الوقوف والإنتظار على حدود الفراغ. & $r$ \\
\hline $1 \leq, V$ & rV & المذاكرة الخارجية فردى ومجموعات. & $\varepsilon$ \\
\hline $17, r$ & $r \cdot$ & الفراغ. الجلوس تحت البرجولات الخفيفة على حدود & 0 \\
\hline r,,$r$ & $\varepsilon$ & الإسترخاء والنوم على العشب الأخضر. & 7 \\
\hline $1 \cdot . r$ & 19 & الجلوس على المقاعد الرخامية. & $\mathrm{V}$ \\
\hline 11,0 & $r \varepsilon$ & المشي والعبور على حلود الفراغ الخارجي. & $\Lambda$ \\
\hline$\varepsilon, 9$ & 9 & العبور من خلال ممرات المشاة داخل الفراغ. & 9 \\
\hline $1 \ldots$ & $1 \wedge \varepsilon$ & 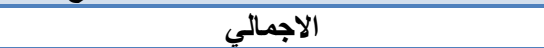 & \\
\hline
\end{tabular}
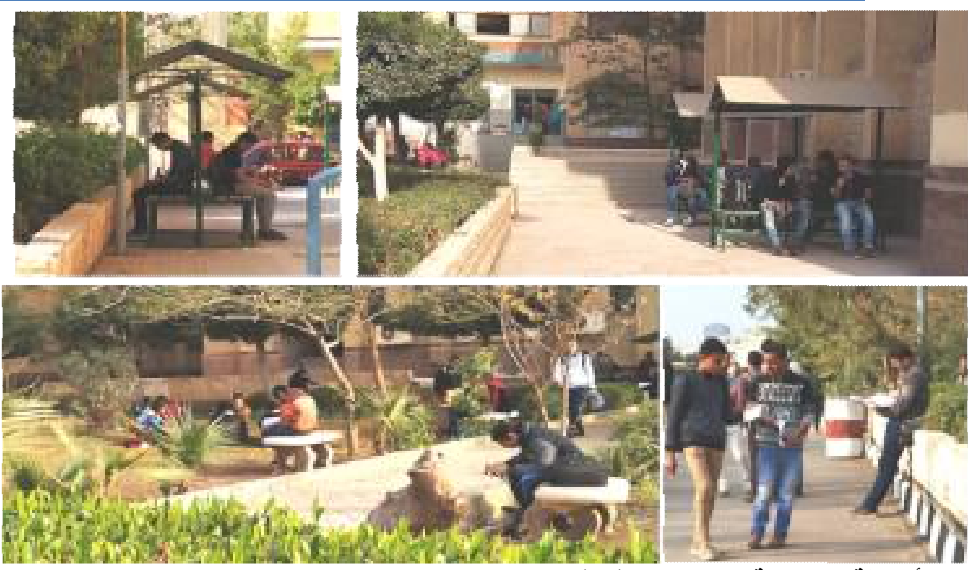

شكل ( • (1) الأنشطة المختلفة داخل الفراغ رقم (r) ).

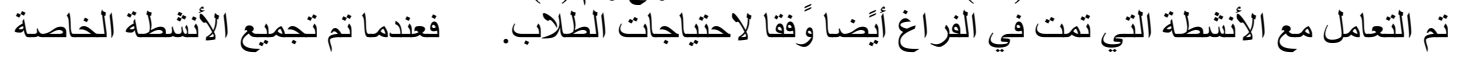
بالاحتياجات، وجد أن أنشطة التنشئة الاجتماعية كانت هي السائدة.

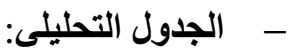

يحتوي على خمسةً عناصر أساسية لفحص العلاقة بين مستوى وطبيعة الأنشطة، استخدام مكونات التصميم ومكان

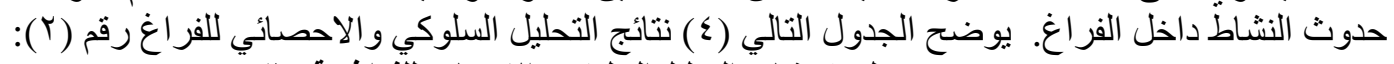

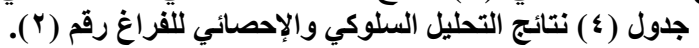

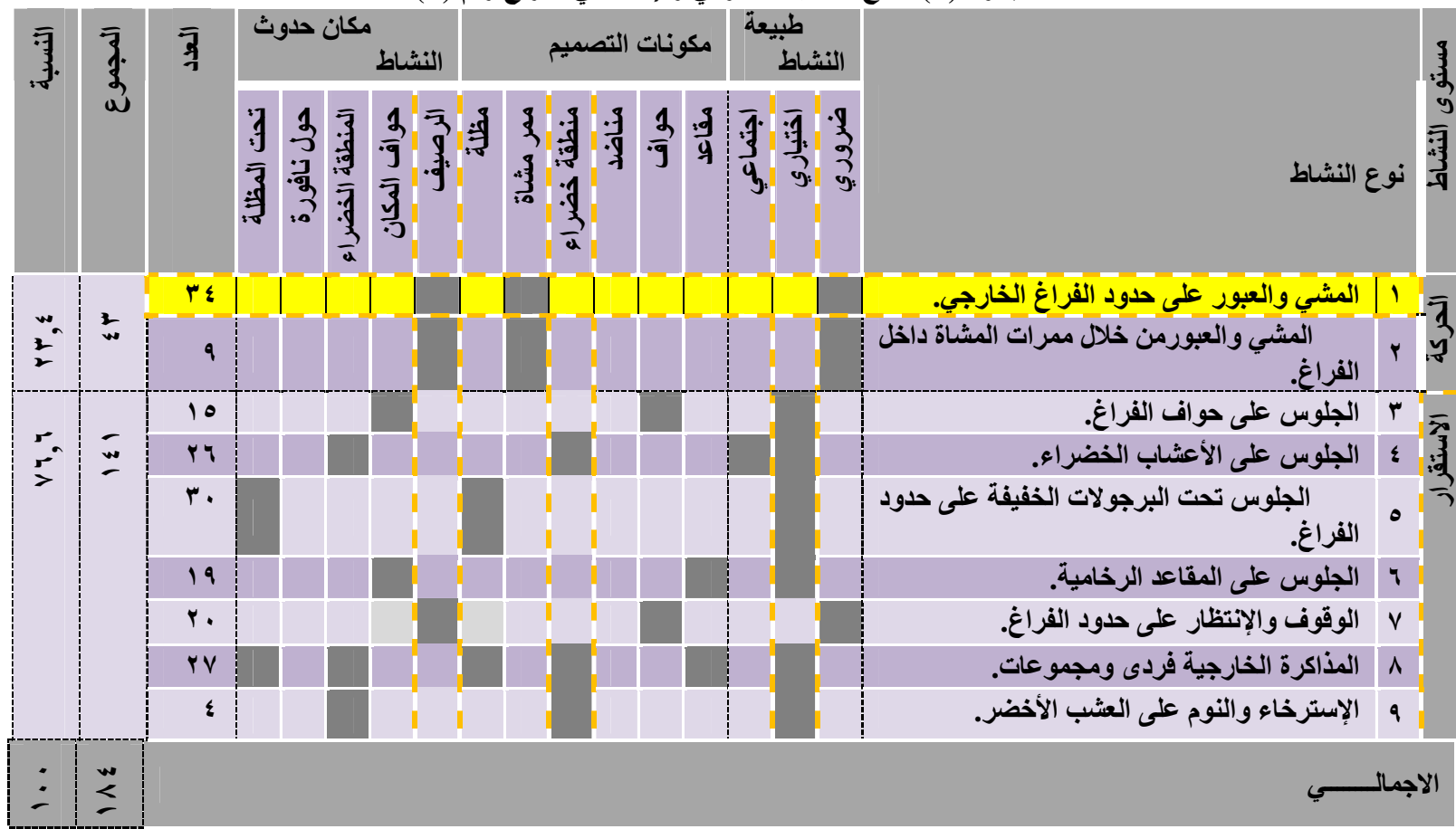




\begin{tabular}{|c|c|c|}
\hline نقاط الضعف: & نقاط القوة: & \\
\hline 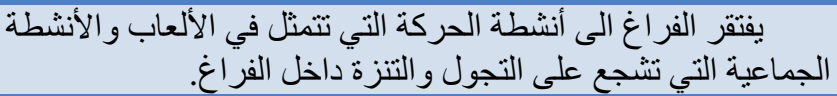 & 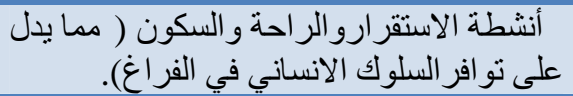 & 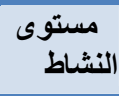 \\
\hline 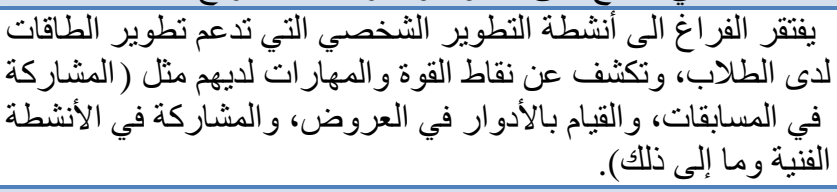 & 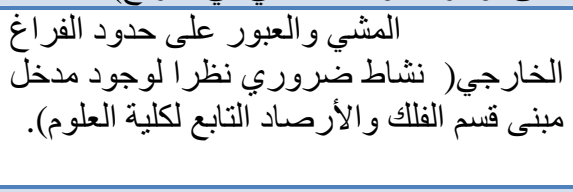 & الميز النشاط \\
\hline 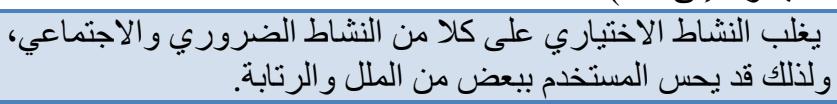 & 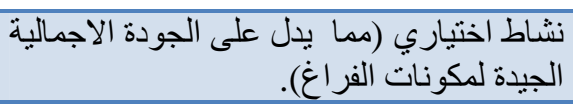 & النثاط طبيعة \\
\hline 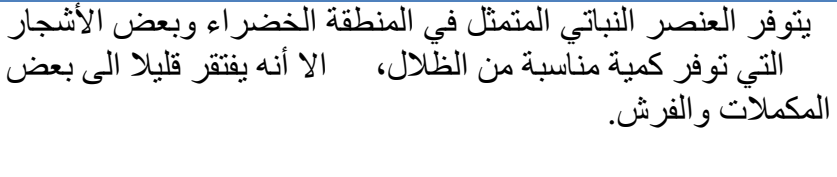 & 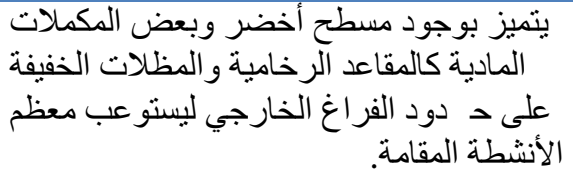 & 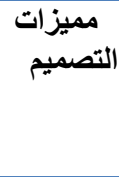 \\
\hline 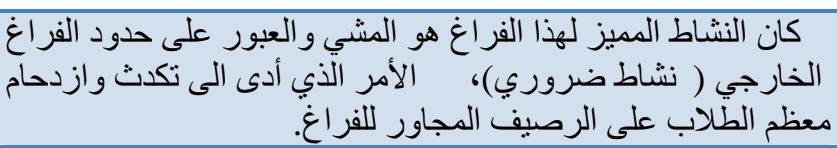 & 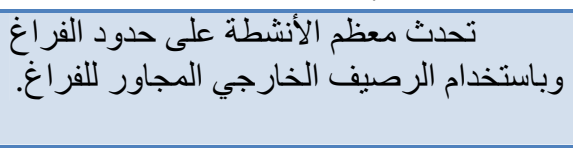 & النشاط حكان \\
\hline
\end{tabular}

- - الخريطة السلوكية: شكل (1) -

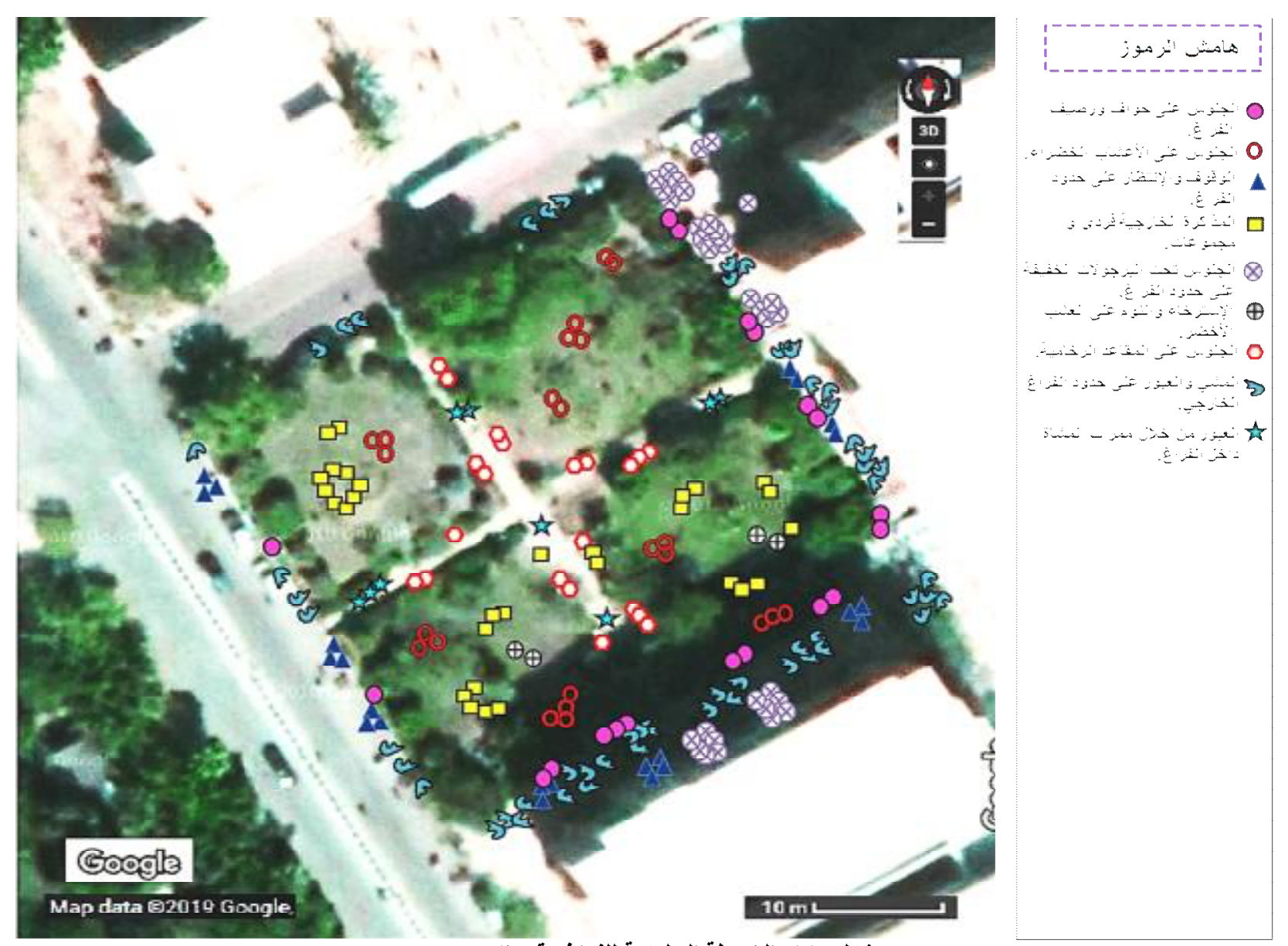

شكل (11) الخريطة السلوكية للفراغ رقم (؟). 


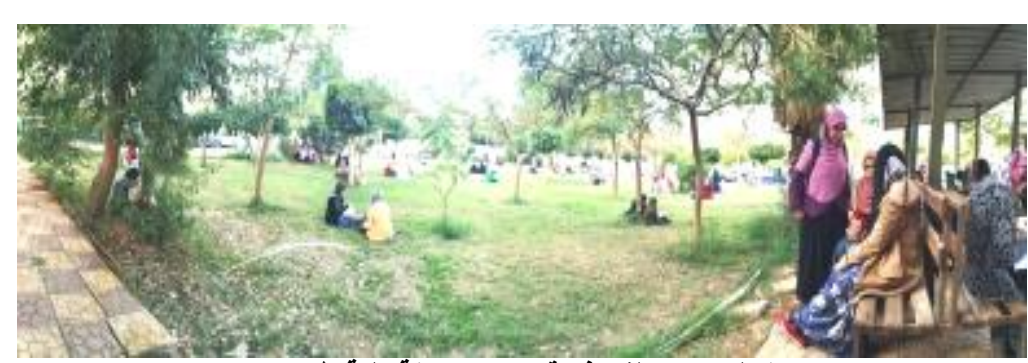

شكل (r ا ) الفراغ رقم (r): حديقة كلية طب بنات.

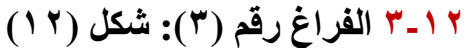

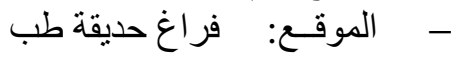
-

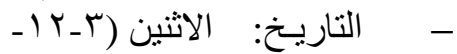
(a)

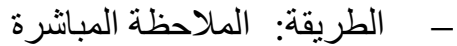
و الخريطة السلوكية.

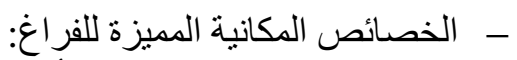

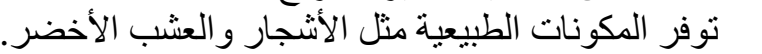

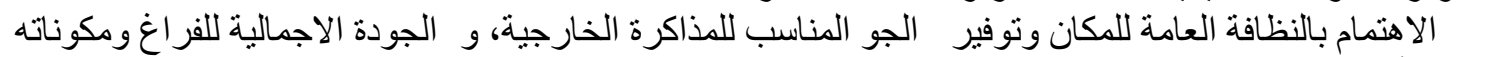
الأساسية جيدة ومرضية للمستخدمين. † مكان آمن للطالبات ومريح من الناحية البصرية و النفسية والتمتع بالهدوء و البعد عن الزحام والضوضناء.

جدول (•) الأنثطة وتردداتها للفراغ رقم (r).

\begin{tabular}{|c|c|c|c|}
\hline النسبة & العدد & الانشطة & \\
\hline$\leqslant V, \leqslant 0$ & 70 & المذاكرة الخارجية في مجموعات. & 1 \\
\hline$\varepsilon, \mu \wedge$ & 7 & أداء فريضة الصلاة. & r \\
\hline $17, \cdot 7$ & rr & الجلوس على الأعشاب والتحدث. & $r$ \\
\hline$r, q 1$ & $\varepsilon$ & التصوير الفوتوغرافي. & $\varepsilon$ \\
\hline$r, q 1$ & $\varepsilon$ & الوقوف والانتظار. & 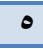 \\
\hline$v, r q$ & $1 \cdot$ & الاسترخاء والتأمل. & 7 \\
\hline $11,7 \mathrm{~V}$ & 17 & الجلوس تحت المظلة. & v \\
\hline$v, r q$ & 1. & المشي والعبور من خلال الفراغ. & $\Lambda$ \\
\hline $1 \ldots$ & IrV & الاجمالي & \\
\hline
\end{tabular}

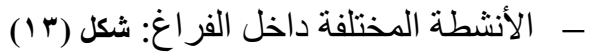

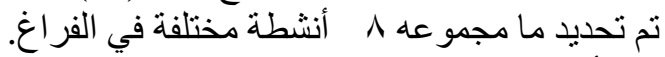

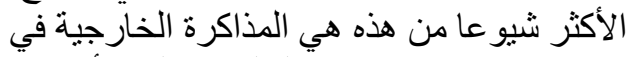

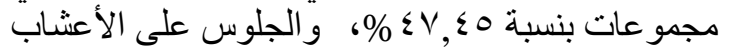

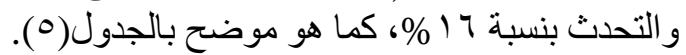

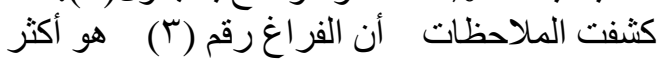

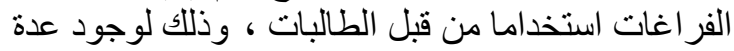

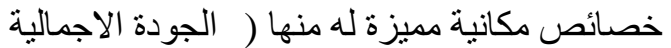

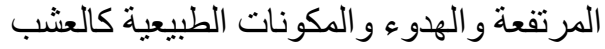

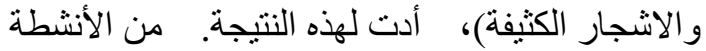

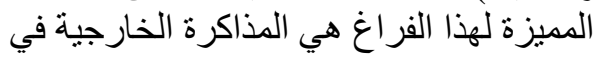

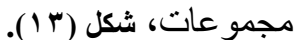
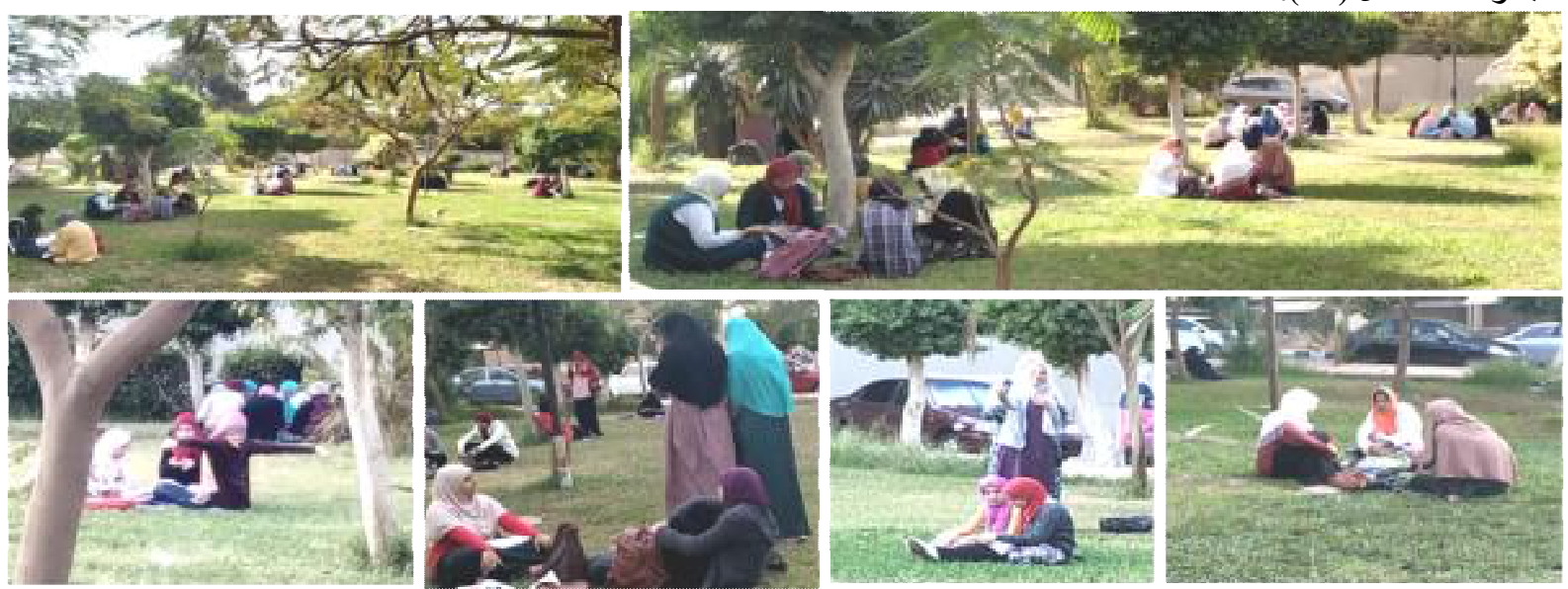

شكل (r ا ) الأنثطة المختلفة داخل الفراغ رقم (r).

تم التعامل مع الأنشطة التي تمت في الفراغ أيضًا وفًا لاحتياجات الطالبات، فعندما تم تجميع الأنشطة الخاصة

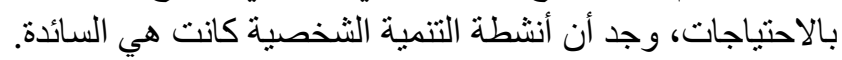

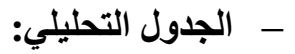

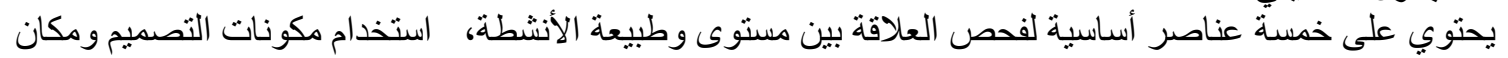

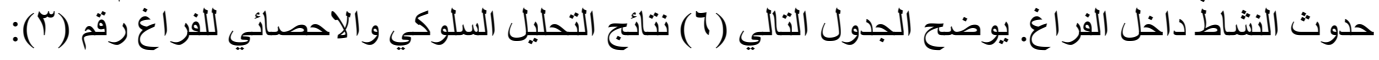


جدول (†) نتائج التحليل السلوكي والإحصائي للفراغ رقم (؟آ).

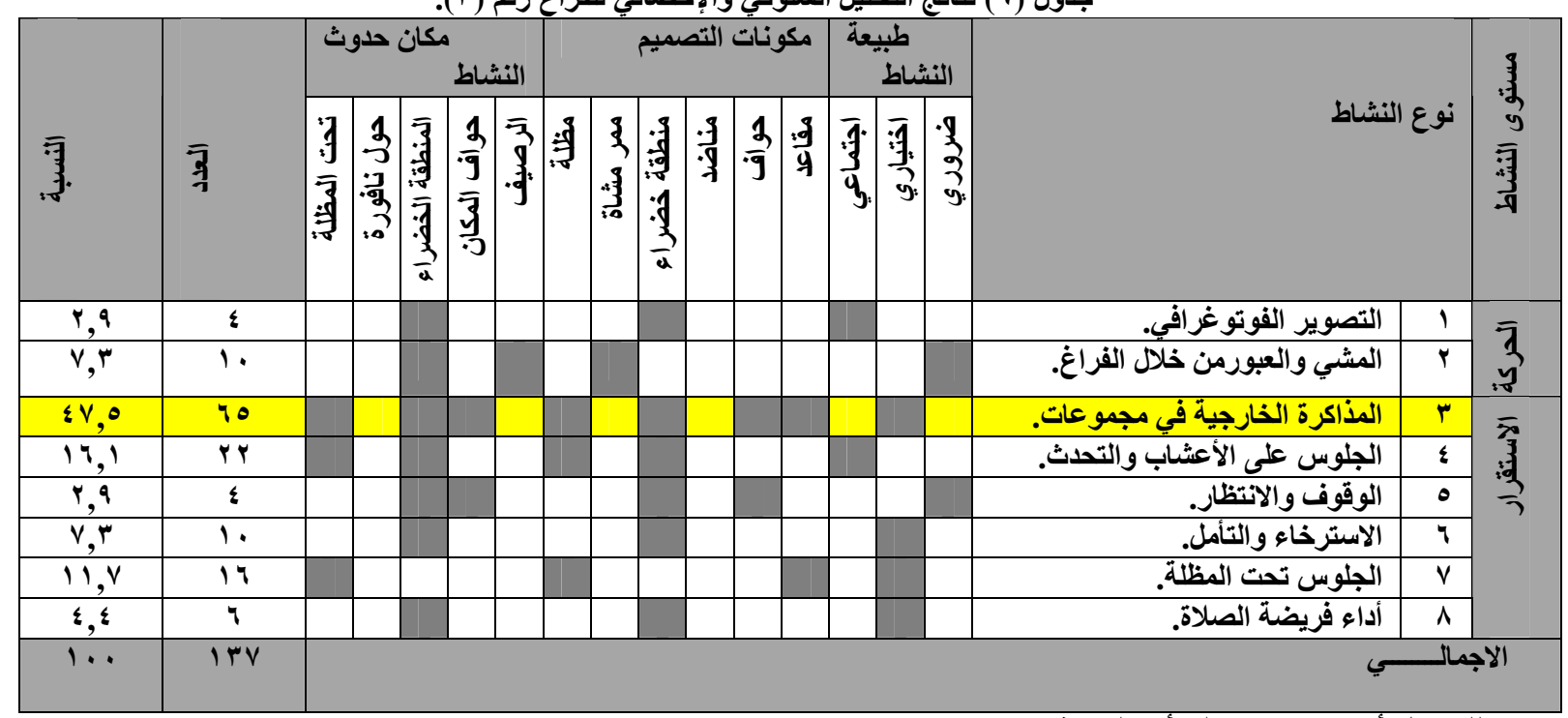

\begin{tabular}{|c|c|c|}
\hline نقاط الضعف: & نقاط القوة: & \\
\hline 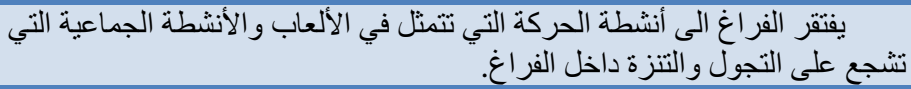 & 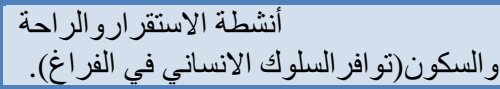 & النشاط مستوى \\
\hline 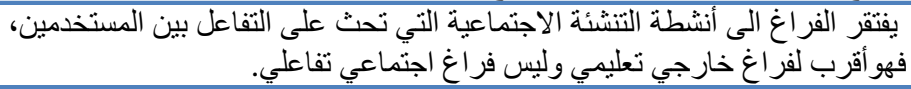 & التطوير الثخصي). الخداية في مجمو عات ( أنشطة & الميز النشاط \\
\hline 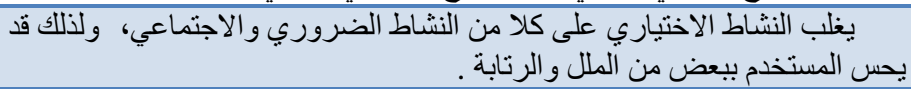 & 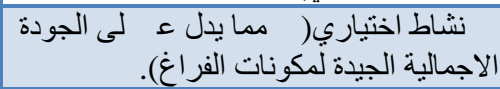 & النشاط طبية \\
\hline 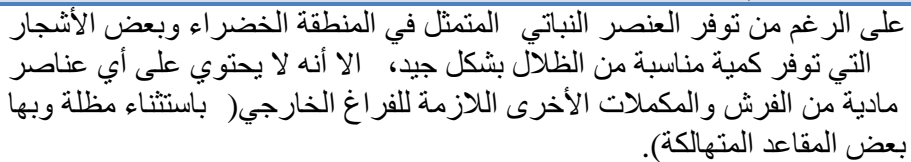 & معظم الأنشطة المقامة. أخضر جذاب يستو عب & التصميز \\
\hline 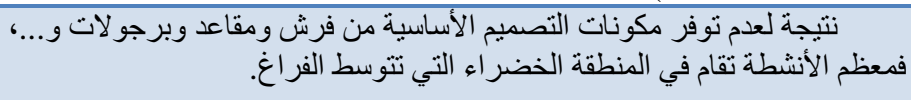 & الخضر اء. عدث معظم الأنشطة داخل الد نطقة & مكان \\
\hline
\end{tabular}

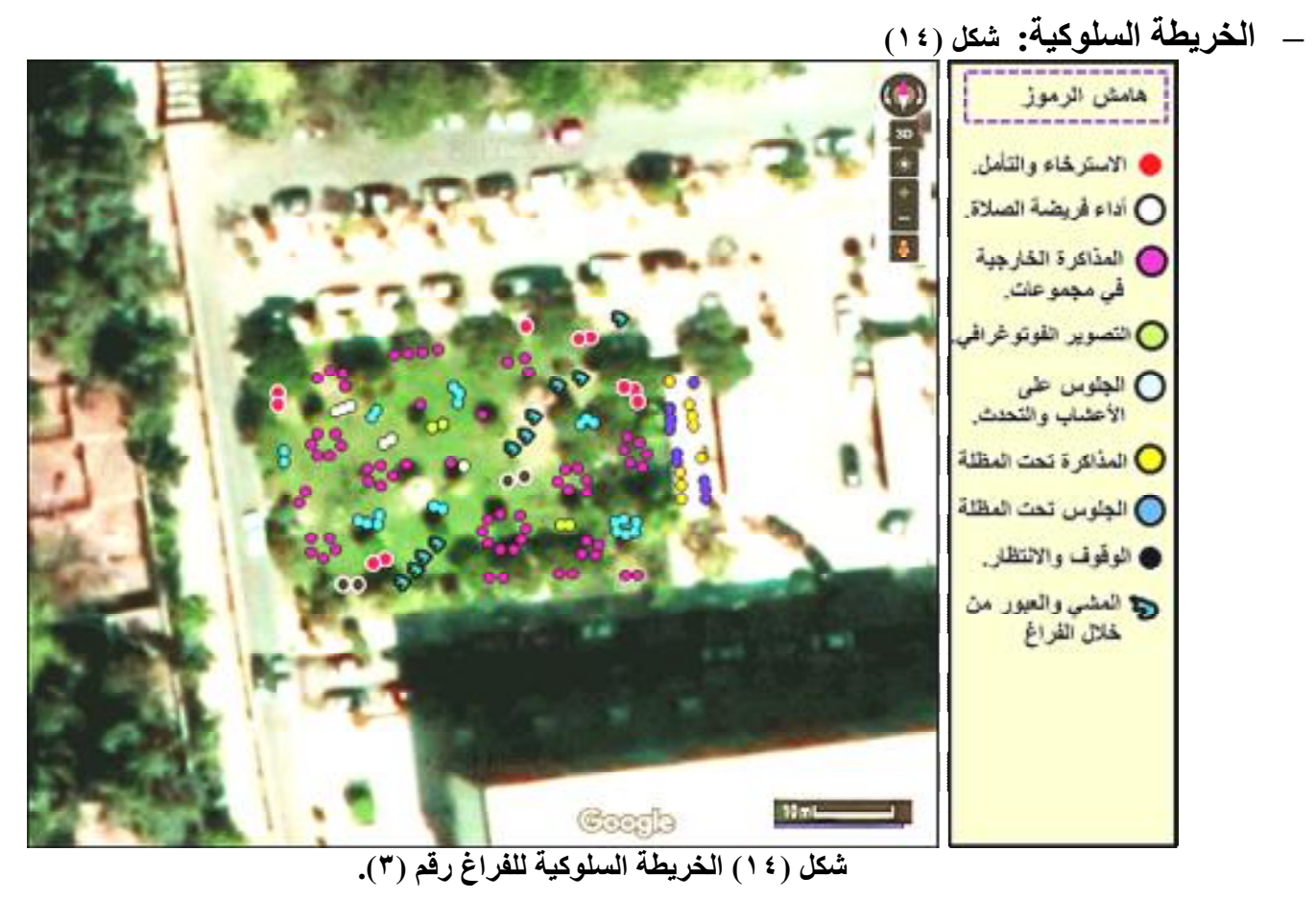




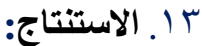

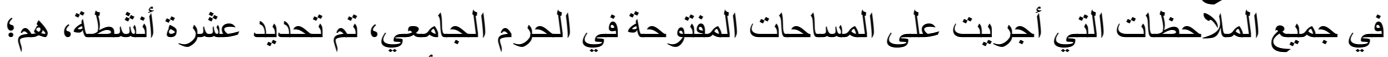

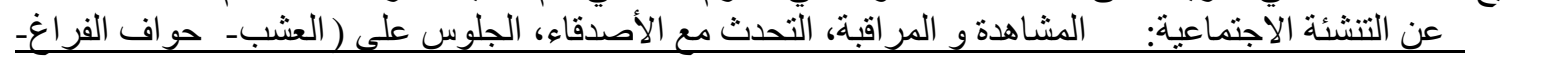

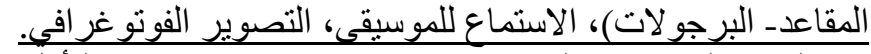

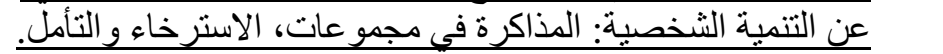

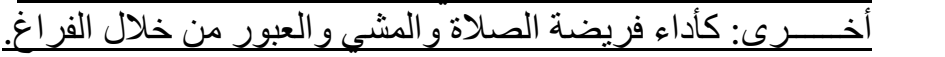

جدول (V) توزيع الأنشطة المميزة للفراغات الثثلاثة المختارة.

\begin{tabular}{|c|c|c|c|}
\hline الممبيزة النشاط & النسبة & النشاط المميز & 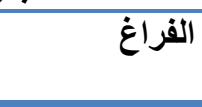 \\
\hline اختياري & $r v, r$ & الجلوس على حواف ورصيف الفراغ. & الفراغ رقم (1) \\
\hline ضروري & 11,0 & المشي والعبور على حدود الفراغ الخارجي. & الفراغ رقم (Y) \\
\hline اختياري & $\varepsilon V, \leqslant 0$ & المذاكرة الخارجية في مجموعات. & الفراغ رقم (ب) \\
\hline
\end{tabular}

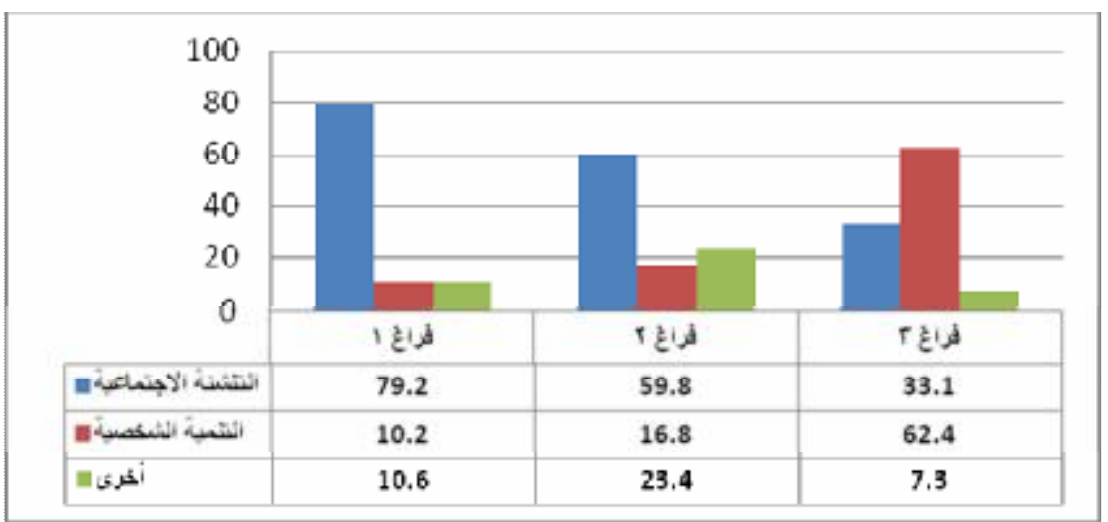

رسم بياني (1) مجموعات الأنشطة وفقا لاحتياجات المستخدمين.

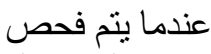

المساحات بشكل مستقل عن بعضها البعض، يكون توزيع الأنشطة المميزة للفر اغات بمعدلها كما يلي:

جدول (v)

في الم لاحظات التي تم إجر اؤها على المساحات المفتوحة في الحرم الما

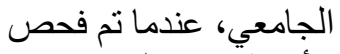
الأنشطة من قبل مجمو عة النشاط وفقا لاحتياجات المستخدمين، تم تحديد أنشطة التنشئة الاجتماعية لتكون هي السائدة، كما هو الأنها موضتح بالرسم البياني

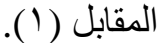

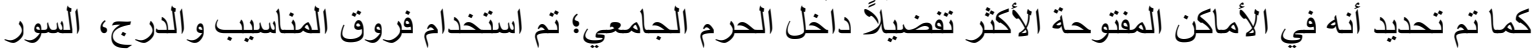

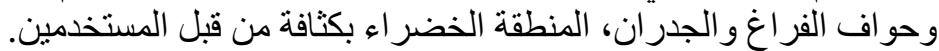
هذا يكثف عن أنه بالإ ضافة الى توفير المكملات و الفرش في تصميم المساحات المفتوحة، يجب أن أن تؤخذ مكونات مكانية

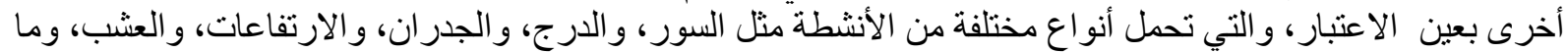

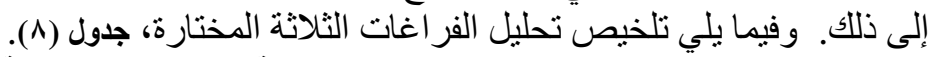
جدول (^) خلاصة تحليل الفراغات الثلاثة المفضلة المختارة.

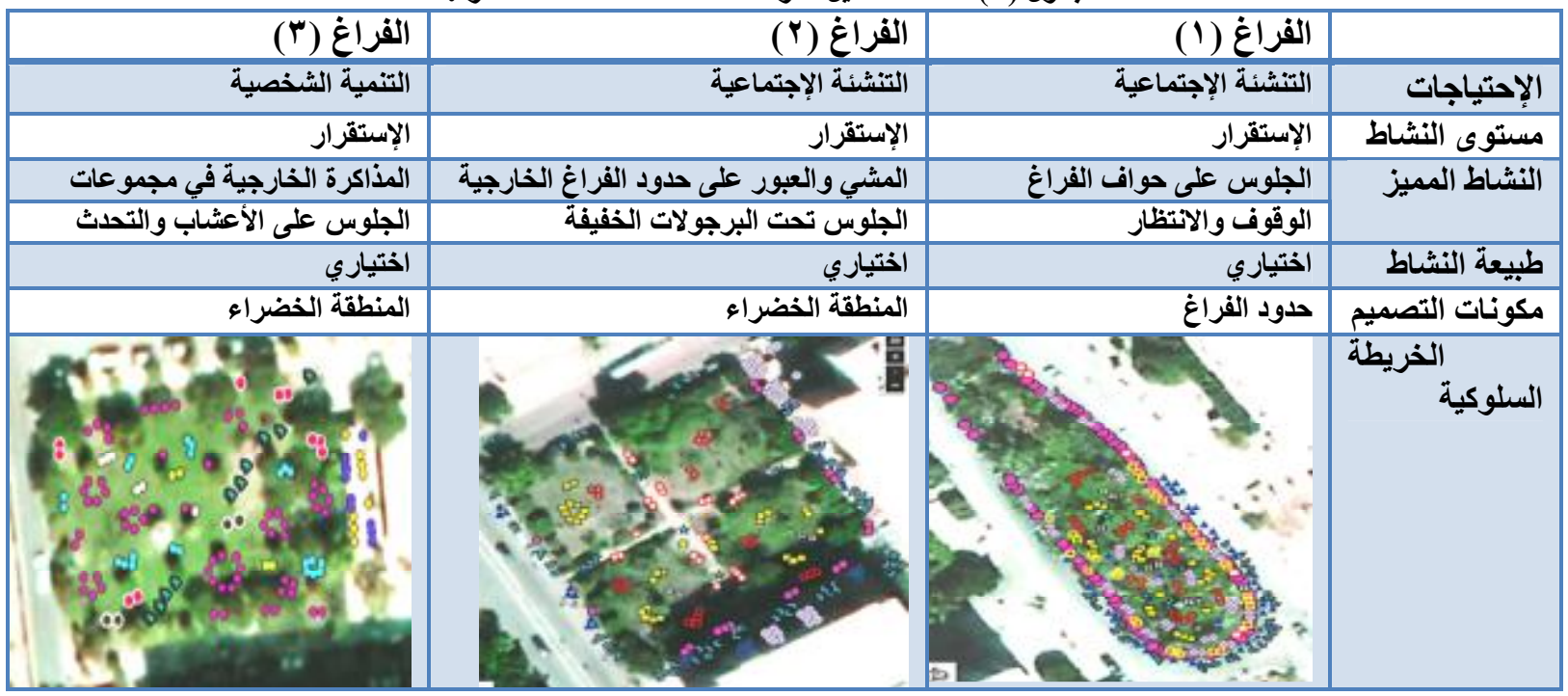




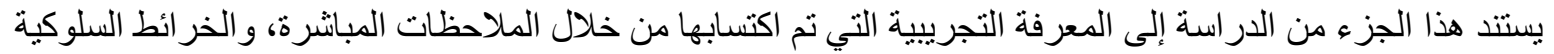

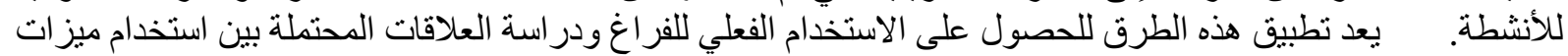

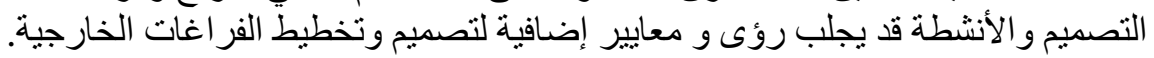

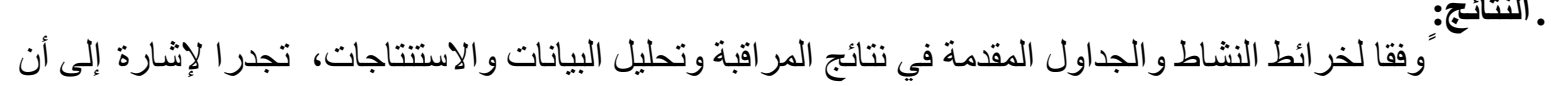

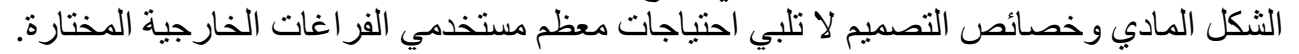

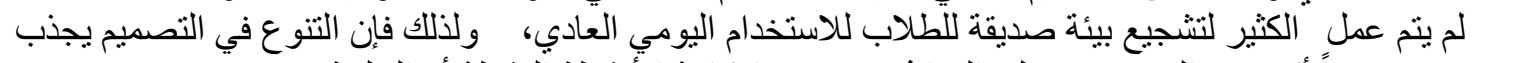

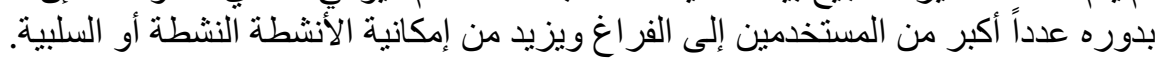

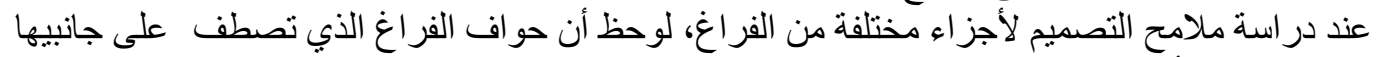

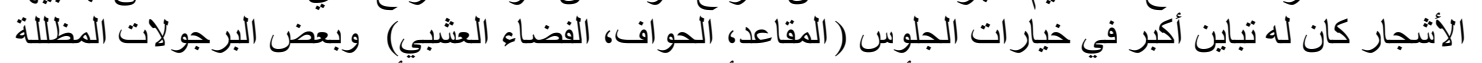

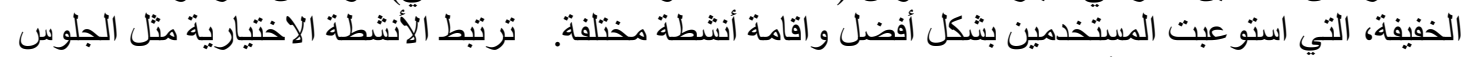

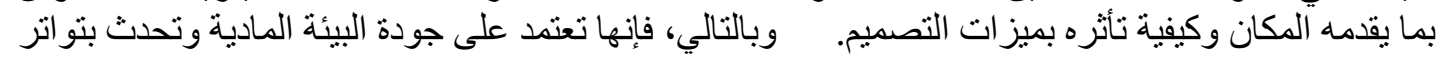

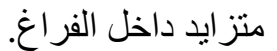

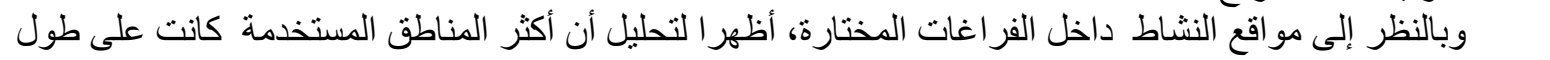

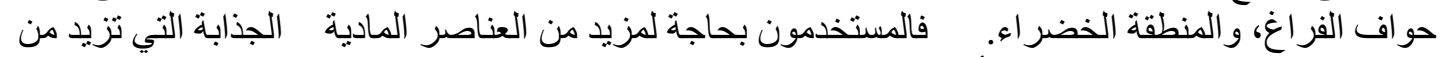

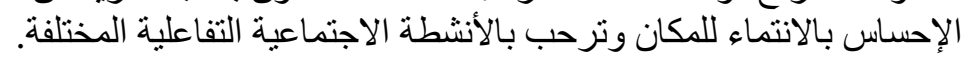

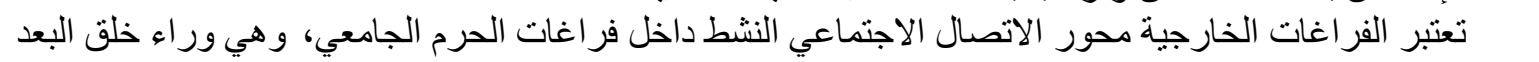

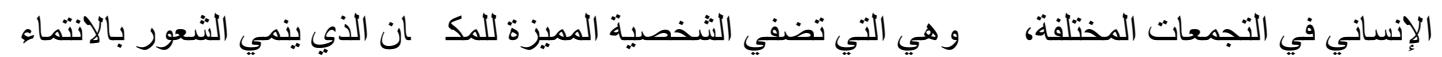

و والارتباط به.

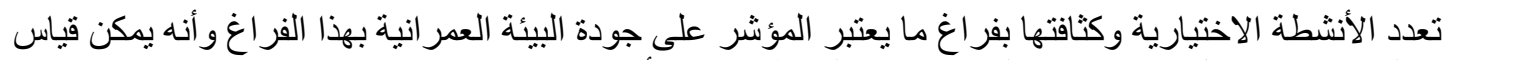

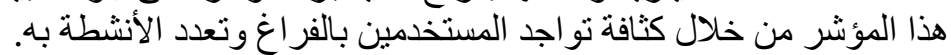

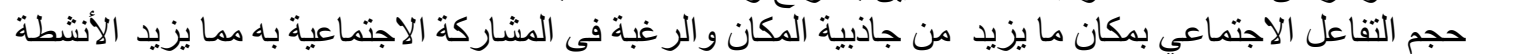

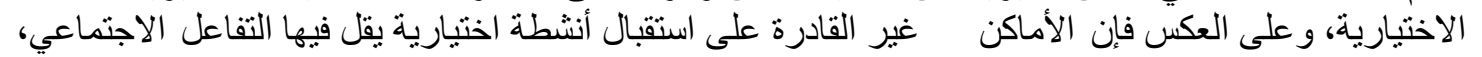

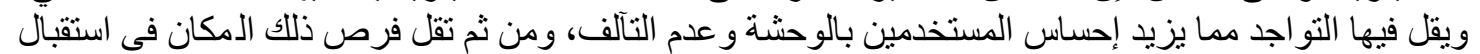
الأنشطة.

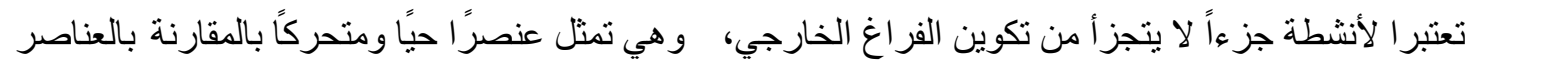

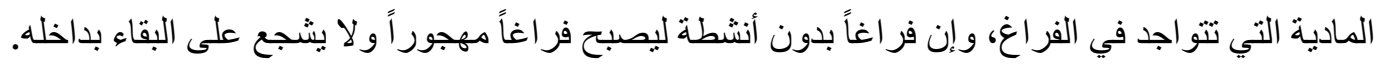

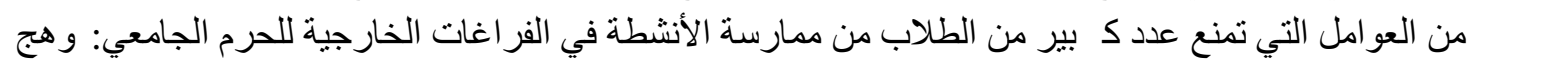

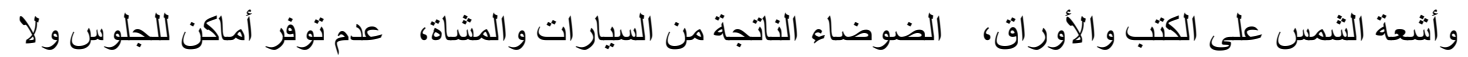
مناضد للكتابة.

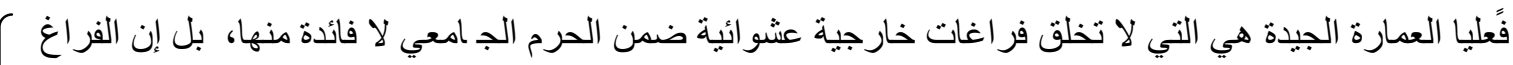

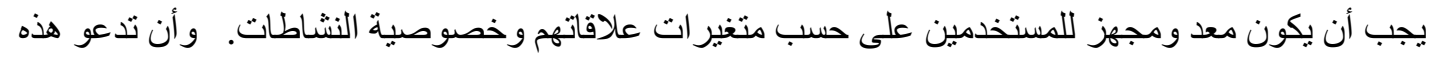
ل الفر اغات لسلوك مثالي باعتبار البيئة الفيزيائية التي نبنيها هي ظاهرة اجتماعية أكثر من كونها بيئة مادية.

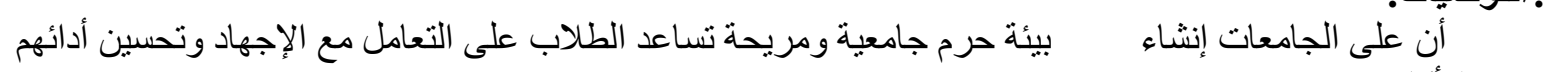

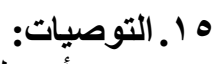

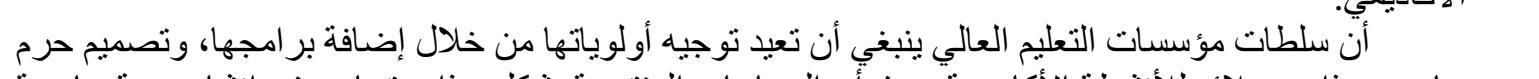

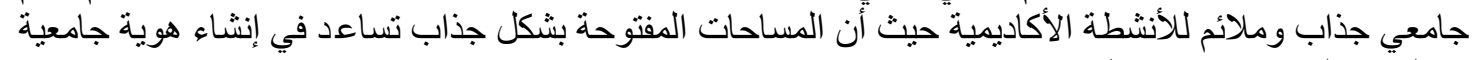

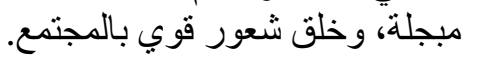

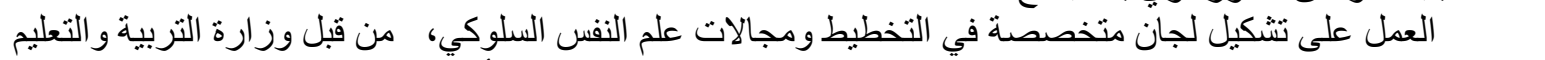

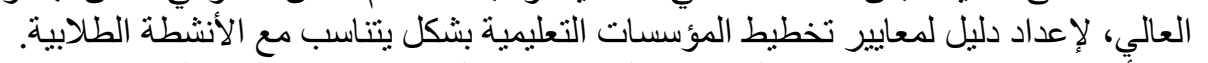

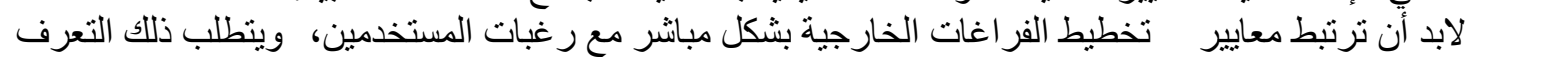

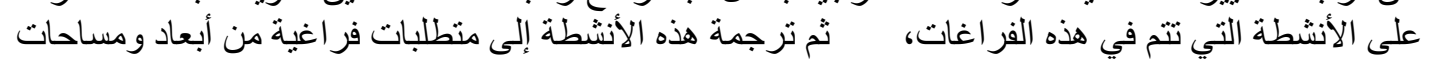
و عناصر فرش مناسبة لها.

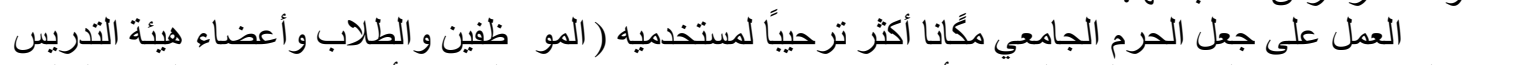

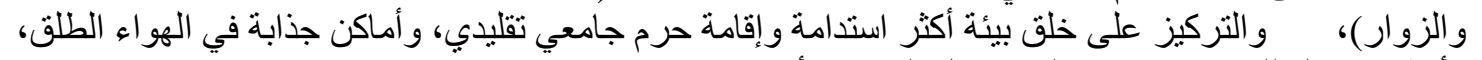
و أنظمة تداول للمشاة بالإضافة إلى وسائل الر احة الأخرى. 


$$
\text { تقييم الفر اغات الخارجية داخل الحرم الجامعي "جامعة الأزهر بمدينة نصر كحالة دراسة" }
$$

† بتطلب تصميم الحرم الجامعي ثلاثة تخصصات هم (هندسة المناظر الطبيعية ، العمارة والتخطيط) تعمل معًا لبناء حرم جامعي ناجح وذو كفاءة عالية.

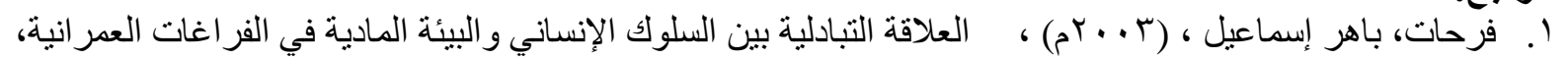

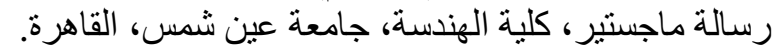

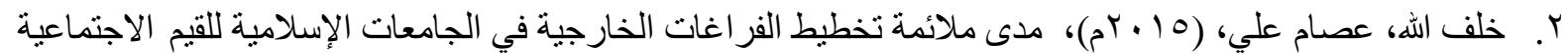

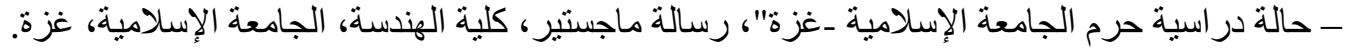

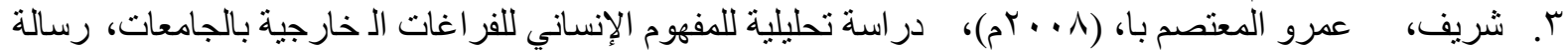
ماجستير، كلية الهندسة، جامعة القاهرة.

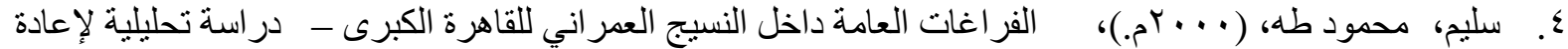

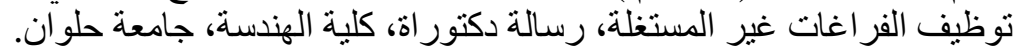

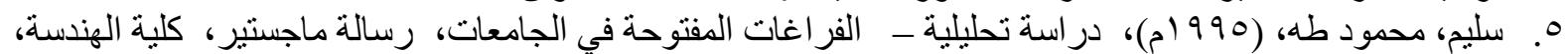
جامعة حلو ان.

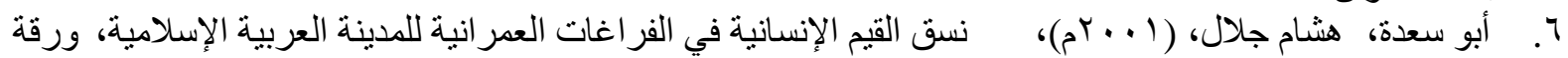

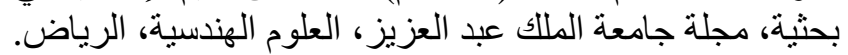

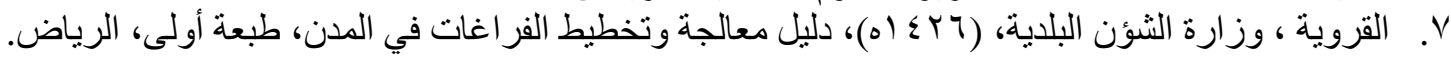

8. Yoshinobu, A. ,( 1981), Exterior Design In Architecture, Van Nostrand Reinhold Company,.

9. Salama, A., M., , (2009), Design Intentions And Users Responses: Assessing Outdoor Spaces Of Qatar University Campus, Open House International, Vol 34, No.1.

10. Salama, A., M., (2012), Assessing Qatar University's Campus Outdoor Spaces: Design Intentions Versus Users' Reactions, Enhancing Building Performance, 1st, Blackwell Publishing, Ltd,.

11. Aydin,D. And Ter, U., (2008), Outdoor Space Quality. Case Study Of A University Campus, Archnet-IJAR, International Journal Of Architectural Research, 2(3), 189-203.

12. Gehl, S. B., (2013), How To Study Public Life, (K. A. Steenhard, Trans.) Washington, Island Press.

13. Gehl, J., (2011), Life Between Buildings: Using Public Space,Kochjo,London,Island Press, 207.

14. Gehl, J., (2013), Cities For People,London,Island Press.

15. Du“Zenli, T., , Mumcu, S., , Serap,Y., (2012), Analyzing Youth's Activity Patterns In Campus Open Spaces Depending On Their Personal And Social Needs, Springer Science+Business Media, LLC , 202. 